\title{
The Mst1 and Mst2 kinases control activation of rho family GTPases and thymic egress of mature thymocytes
}

\section{Citation}

Mou, Fan, Maria Praskova, Fan Xia, Denille Van Buren, Hanno Hock, Joseph Avruch, and Dawang Zhou. 2012. The Mst1 and Mst2 kinases control activation of rho family GTPases and thymic egress of mature thymocytes. The Journal of Experimental Medicine 209(4): 741-759.

\section{Published Version}

doi:10.1084/jem.20111692

\section{Permanent link}

http://nrs.harvard.edu/urn-3:HUL.InstRepos:10504659

\section{Terms of Use}

This article was downloaded from Harvard University's DASH repository, and is made available under the terms and conditions applicable to Other Posted Material, as set forth at http:// nrs.harvard.edu/urn-3:HUL.InstRepos:dash.current.terms-of-use\#LAA

\section{Share Your Story}

The Harvard community has made this article openly available.

Please share how this access benefits you. Submit a story.

\section{Accessibility}




\title{
The Mst1 and Mst2 kinases control activation of rho family GTPases and thymic egress of mature thymocytes
}

\author{
Fan Mou, ${ }^{1,2,4}$ Maria Praskova,,${ }^{1,2,4}$ Fan Xia, ${ }^{1,2,4}$ Denille Van Buren, ${ }^{3,4}$ \\ Hanno Hock, ${ }^{3,4}$ Joseph Avruch, ${ }^{1,2,4}$ and Dawang Zhou ${ }^{1,2,4}$
}

'Department of Molecular Biology; ${ }^{2}$ Diabetes Unit, Medical Services; and ${ }^{3}$ Cancer Center; Massachusetts General Hospital, Boston, MA 02114

${ }^{4}$ Department of Medicine, Harvard Medical School, Boston, MA 02115

The Mst1 kinase is an important regulator of murine T cell adhesion, migration, proliferation, and apoptosis. In this study, we analyze mice lacking both Mst1 and Mst2 in hematopoietic cells. Compared with wild-type mice, these double knockout (DKO) mice exhibit a severe reduction in the number of mature $T$ cells in the circulation and in secondary lymphoid organs (SLOs). $\mathrm{CD}^{+}{ }^{+} \mathrm{CD8} 8^{-}$and $\mathrm{CD} 4^{-}{ }^{-} \mathrm{CD} 8^{+}$single-positive (SP) thymocytes in DKO mice resemble mature $T$ cells of wild-type mice but undergo excessive apoptosis, and their egress from the thymus is reduced by $>\mathbf{9 0} \%$. Even when placed directly in the circulation, DKO SP thymocytes failed to enter SLOs. In SP thymocytes, deficiency of Mst1 and Mst2 abolished sphingosine-1 phosphate- and CCL21-induced Mob1 phosphorylation, Rac1 and RhoA GTP charging, and subsequent cell migration. When phosphorylated by Mst1 or Mst2, Mob1 binds and activates the Rac1 guanyl nucleotide exchanger Dock8, which is abundant in the thymus. Thus, the Mst1 and Mst2 kinases control Rho GTPase activation and the migratory responses of SP thymocytes.

\section{CORRESPONDENCE}

Joseph Avruch:

avruch@molbio.mgh.harvard.edu $\mathrm{OR}$

Dawang Zhou:

dwzhou@xmu.edu.cn

Abbreviations used: DP, double positive; GEF, guanyl nucleotide exchange factor; OKA, okadaic acid; S1P, sphingosine-1 phosphate; shRNA, short hairpin RNA; SLO, secondary lymphoid organ; SP, single positive.
Lymphoid precursors migrate from liver and bone marrow to thymus, where they develop into $\mathrm{CD}^{+}$or $\mathrm{CD}^{+} \mathrm{T}$ cells through a choreographed set of intrathymic migrations (Takahama, 2006; Petrie and Zúñiga-Pflücker, 2007; Bunting et al., 2011; Love and Bhandoola, 2011) that accompany maturation of the TCR, followed by positive and negative selection of antigen specificity (von Boehmer et al., 2003). Mature thymocytes enter the venous circulation and traffic to secondary lymphoid organs (SLOs), awaiting an antigenic stimulus (Drennan et al., 2009; Bunting et al., 2011; Love and Bhandoola, 2011). T cell trafficking is critical to immune surveillance and to the generation of an effective immune response (Bromley et al., 2008). This trafficking is mediated by a set of chemotactic receptors, adhesion molecules, the cellular actin network, and its regulators.

Recent work has established the Mst1 kinase as an important regulator of $\mathrm{T}$ cell adhesion, migration, proliferation, and apoptosis (Zhou et al., 2008; Choi et al., 2009; Dong et al., 2009; Katagiri et al., 2009). The murine Mst1 and Mst2 kinases are most abundant in tissues of the lymphoid system, and mice lacking Mst1 exhibit a variety of $\mathrm{T}$ cell abnormalities. Among the most prominent is an $\sim 50 \%$ reduction in the number of $\mathrm{CD} 62 \mathrm{~L}^{\text {hi }} \mathrm{CD} 44^{\text {lo }}$ mature naive $\mathrm{T}$ cells in SLOs, with little change in the number of CD62L ${ }^{\mathrm{lo}} \mathrm{CD} 44^{\text {hi }}$ effector/memory T cells; available evidence supports several contributory mechanisms. Whereas thymic development in Mst1-null mice is largely unaltered, single-positive (SP) thymocytes are modestly increased and show a diminished egress in vivo after labeling with FITC as well as in vitro in response to CCL19, CCL21, CXCL12, and CCL25 (Dong et al., 2009). In addition, although selectin-mediated rolling of Mst1-null naive $\mathrm{T}$ cells on endothelium is intact, their ability to adhere to high endothelial venules and enter peripheral LNs is reduced by $\sim 65 \%$, a defect largely attributable to their inability to activate the integrins LFA-1 and MAdCAM-1

Q 2012 Mou et al. This article is distributed under the terms of an AttributionNoncommercial-Share Alike-No Mirror Sites license for the first six months after the publication date (see http://www.rupress.org/terms). After six months it is
the available under a Creative Commons License (Attribution-Noncommercial-Share Alike 3.0 Unported license, as described at http://creativecommons.org/licenses/ by-nc-sa/3.0/) 
in response to chemokines (Katagiri et al., 2009). Mst1-null $\mathrm{T}$ cells also show diminished migration on immobilized chemokines and within explanted LNs. As first shown by Katagiri et al. (2006), Mst1 in T cells is found in a 1:1 complex with the RAPL/Nore1B/Rassf5B polypeptide, a Rap1-GTP-binding protein (Praskova et al., 2004; Avruch et al., 2009). Chemokine or T cell receptor activation promotes Rap1-GTP charging and recruits the RAPL-Mst1 complex to the leading edge. There the RAPL-Mst1 complex binds to and clusters LFA-1; T cells deficient in either RAPL (Katagiri et al., 2004) or Mst1 (Zhou et al., 2008; Katagiri et al., 2009) do not exhibit LFA-1 clustering in response to chemokines or TCR activation. The biochemical mechanism by which Mst1 promotes LFA-1 activation is not known.

Mst1-deficient naive T cells also show a greatly enhanced proliferative response to TCR stimulation and higher levels of ongoing apoptosis in vivo, another likely contributor to their low numbers in vivo. Notably, the levels of Mst1 polypeptide are reduced by 10-fold in the normal transition from naive to effector cell. Thus, Mst1 is a negative regulator of the commitment of naive $\mathrm{T}$ cells to a proliferative response upon TCR activation (Zhou et al., 2008). Mst1 is homologous to the Drosophila melanogaster kinase hippo, which inhibits cell proliferation in response to cell-cell contact by negative regulation of the transcriptional co-activator yorkie (Pan, 2010; Halder and Johnson, 2011). The mechanism of the antiproliferative effect of Mst1 in naive T cells is unknown, inasmuch as the mammalian yorkie orthologue Yap1 does not participate in the proliferative response of naive $\mathrm{T}$ cells to TCR/CD28 co-stimulation (Zhou et al., 2008).

In this study, we characterize the effect of the combined elimination of Mst1 and Mst2 from the lymphoid compartment; whereas $\mathrm{T}$ cell development proceeds normally, the ability of SP thymocytes to exit is severely inhibited, and they exhibit a high rate of intrathymic apoptosis. Chemokines and sphingosine-1 phosphate (S1P) fail to activate rho family small GTPases or polarize the actin cytoskeleton in the Mst1/Mst2-deficient SP thymocytes, and their migratory responses are profoundly inhibited. The phosphorylation of Mst1/Mst2 substrates Mob1A and Mob1B (see Materials and methods for a description of Mob1A/B nomenclature) is lost entirely. The $25-\mathrm{kD}$ noncatalytic Mob1A/B polypeptides, consequent to their phosphorylation by Mst1/Mst2, are known to bind and activate ndr family kinases (Praskova et al., 2008; Hergovich, 2011). We find that phospho-Mob1A/B also bind specifically and activate the Dock8 guanyl nucleotide exchanger. In thymocytes, CCL19 stimulates thymocyte Mob1A/B phosphorylation in an Mst1/Mst2dependent manner and promotes phospho-Mob1A/B binding to endogenous Dock8. We propose that the inability of the Mst1/ Mst2-deficient T cells to recruit Dock8 contributes to the failure of rho GTPase activation, actin regulation, and thymic egress.

\section{RESULTS}

Deletion of Mst1 and Mst2 from the lymphoid compartment reduces peripheral T cell number by $98 \%$

In contrast to the reduced numbers of naive $T$ cells seen with deletion of Mst1, a global deletion of murine Mst2 caused no changes in lymphocyte numbers in any compartment, nor did Mst2 deletion alter the abundance of Nore1b/RAPL/Rassf5b or the phosphorylation of Mob1 in the thymus (Fig. 1 A). Mst1-null/Mst2ff mice were crossed with mice expressing cre recombinase driven by a vav promoter (de Boer et al., 2003), resulting in inactivation of the Mst 2 gene in the entire hematopoietic lineage. These mice were born at a normal ratio and survived weaning without difficulty. In addition to the loss of Mst2, thymic expression of Nore1b in the vav-cre/Mst1-null/ Mst2 ${ }^{\mathrm{ff}}$ mice (henceforth called Mst1/Mst2vavDKO) was essentially eliminated, as was Mob1A/B phosphorylation (Fig. 1 A). Peripheral blood counts showed that the number of circulating lymphocytes was reduced to $<10 \%$ of WT in the Mst1/Mst2vavDKO mice (Fig. 1 B). The thymus of the Mst1/ Mst2vavDKO mice was slightly smaller than WT, and the total numbers of thymocytes were not significantly decreased (Fig. 1, C and D). As regards T cells, the number of circulating $\mathrm{CD}^{+}$and $\mathrm{CD}^{+}$cells in the Mst1/Mst2vavDKO was $<2 \%$ and $1 \%$, respectively, of WT levels. Similarly, $\mathrm{CD}^{+}{ }^{+}$and $\mathrm{CD}^{+}$ $\mathrm{T}$ cell numbers in the spleen and LNs were also reduced by $>98 \%$ (Fig. 1 D). The morphology of the SLOs reflects the severe depletion of peripheral $\mathrm{T}$ cells; there was a complete loss of white pulp in the spleens of the Mst1/Mst2vavDKO mice, and their LNs were atrophic (not depicted). The preserved number of $\mathrm{CD}^{+}$and $\mathrm{CD}^{+} \mathrm{SP}$ thymocytes together with the severe deficiency of peripheral $\mathrm{T}$ cells indicates that $\mathrm{T}$ cell development in the Mst1/Mst2vavDKO mice has occurred successfully, but egress from the thymus, which is partially impaired in Mst1-null mice (Dong et al., 2009), is inhibited to a much greater extent in the Mst1/Mst2vavDKO mice.

\section{Transgenic WT but not kinase-inactive Mst1 restores peripheral T cell number in Mst1/Mst2 DKO mice}

The deficiency of peripheral $\mathrm{T}$ cells seen in the Mst1-null and especially in the Mst1/Mst2vavDKO mice can be entirely corrected by restoration of a catalytically active Mst1 kinase. Thus, transgenic expression of an Mst1 cDNA driven by the CD2 promoter in Mst1-null and Mst1/Mst2vavDKO mice (Fig. 2 A) restored to WT levels the number and balance of mature, naive $\mathrm{CD}^{+}$and $\mathrm{CD}^{+} \mathrm{T}$ cells in the spleen (Fig. 2, B and C). The abundance of Nore1b was also restored to near-WT levels, as was the extent of phosphorylation of Mob1A/B (Fig. 2 A). In contrast, transgenic expression of a catalytically inactive, ATP site Mst1 mutant (Mst1[K59R]) in Mst1-null mice, although restoring Nore1b expression to normal, further reduced Mob1A/B phosphorylation and worsened the deficiency of peripheral naive $\mathrm{T}$ cells toward the levels seen in the Mst1/Mst2vavDKO mice (Fig. 2, B and C). Thus, it is the lack of Mst1 catalytic activity rather than of Nore1b that underlies the phenotype of Mst1 and Mst1 + Mst2 deficiency in the T cell compartment.

\section{Mst1 and Mst2 abundance and activity increase markedly in SP thymocytes of WT mice}

Mst1 and Mst2 abundance was low in $\mathrm{CD}^{+}{ }^{+} \mathrm{CD} 8^{+}$doublepositive (DP) WT thymocytes and increased markedly and 
to a similar extent in $\mathrm{CD}^{+}$and $\mathrm{CD}^{+} \mathrm{SP}$ thymocytes; the abundance of Nore1b increased in parallel (Fig. $3 \mathrm{~A}$ ). The low expression of Mst1 and Mst2 in DP as compared with SP thymocytes suggests that these kinases are likely to have little or no role in thymocyte development up through the DP stage. The activity of Mst1/Mst2 was also low in the DP thymocytes and much higher in the SP thymocytes, as indicated by the increase in the phosphorylation of the Mst1 and
Mst2 activation loops (identical in amino acid sequence) and by the extent of phosphorylation of Mob1A/B at the sites catalyzed specifically by Mst1 and Mst2 (Praskova et al., 2008; Zhou et al., 2008, 2009). FoxO1 and FoxO3 are other documented substrates of Mst1/Mst2 (Lehtinen et al., 2006); however, neither the abundance of FoxO3 nor the extent of FoxO1/3 phosphorylation at the site catalyzed by Mst1/ Mst2 was altered in SP as compared with DP thymocytes.

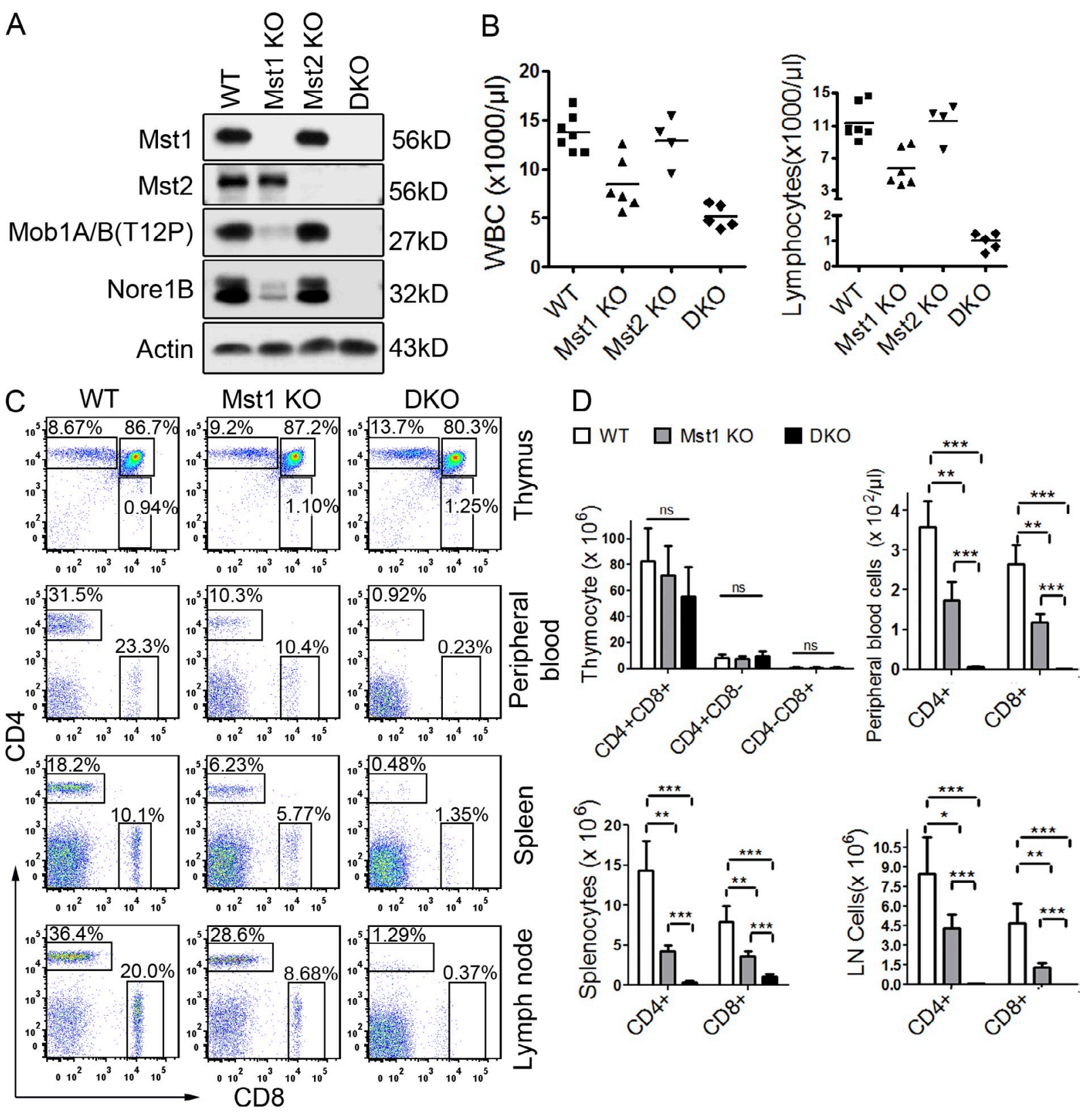

Figure 1. Deletion of Mst1 and Mst2 causes lymphopenia. (A) Thymic extracts from WT (Vav-Cre+Mst1+/+Mst2+/+ mice) Mst1-null (KO), and Vav$\mathrm{Cre}^{+} \mathrm{Mst1}^{-1-M s t 2 f f}$ (DKO) mice were analyzed by Western blot. T12 followed by P indicates phosphorylation. (B) White blood cell (WBC) and circulating lymphocyte counts in mice described in A. Each dot represents an individual mouse, and horizontal bars indicate the mean. (C and D) Single cell suspensions from the thymus, spleen, LN, and peripheral blood were analyzed by flow cytometry. (C) Representative dot plots. (D) Absolute numbers of the indicated populations. Comparisons were performed using the Student's $t$ test $\left.{ }^{*}, P<0.05 ;{ }^{* *}, P<0.01 ;{ }^{* * *}, P<0.001\right)$. Each bar represents combined results from three mice of the indicated genotype. Error bars indicate \pm SEM. 
A
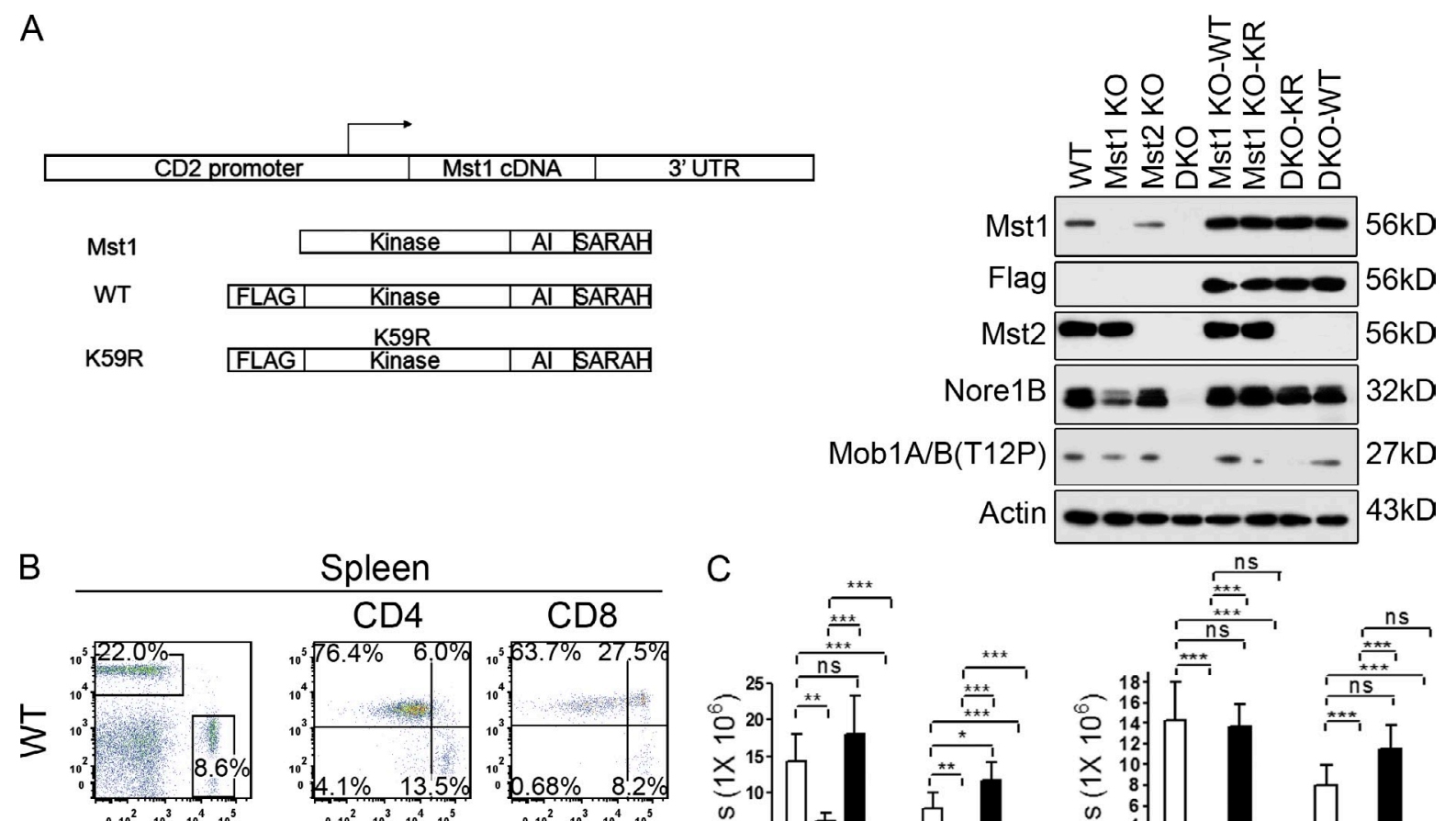

Spleen

Mst1 cDNA

3'UTR

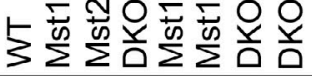

\begin{tabular}{|c|c|c|c|}
\hline Mst1 & & Kinase & Al SARAH \\
\hline WT & FLAG & Kinase & Al SARAH \\
\hline K59R & FLAG & $\begin{array}{l}\text { K59R } \\
\text { Kinase }\end{array}$ & Al $\mathrm{SA}$ \\
\hline
\end{tabular}
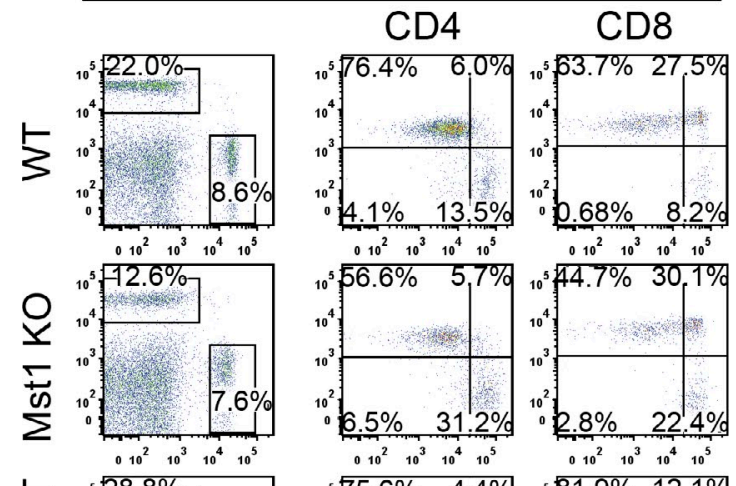

C
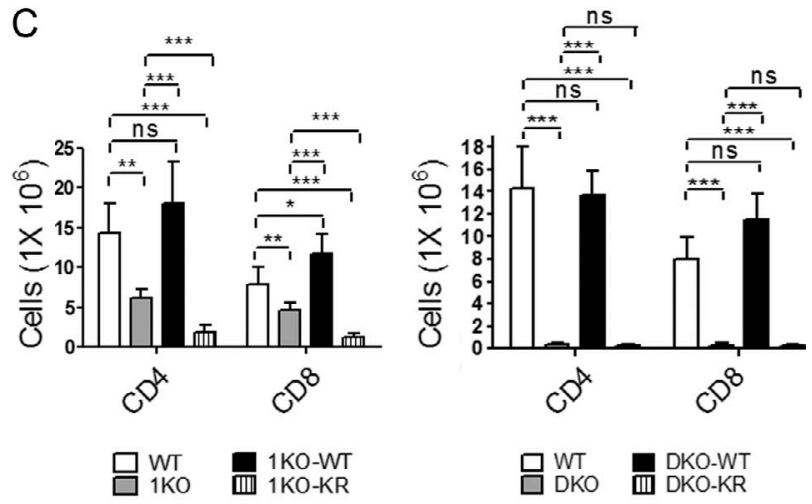

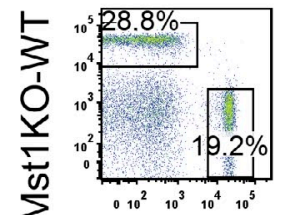
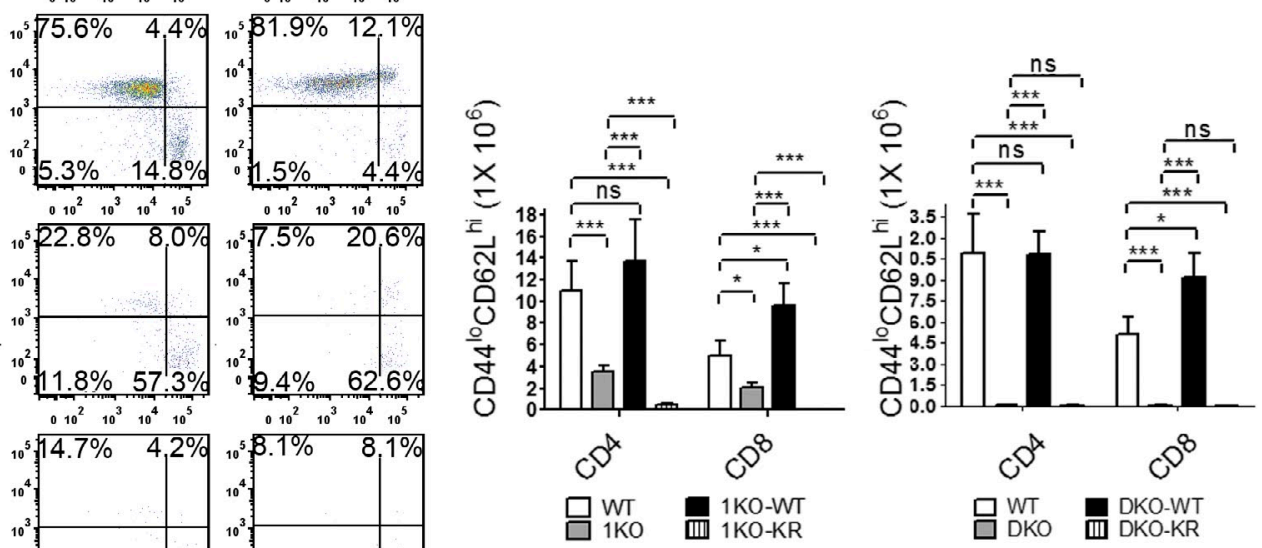

옴
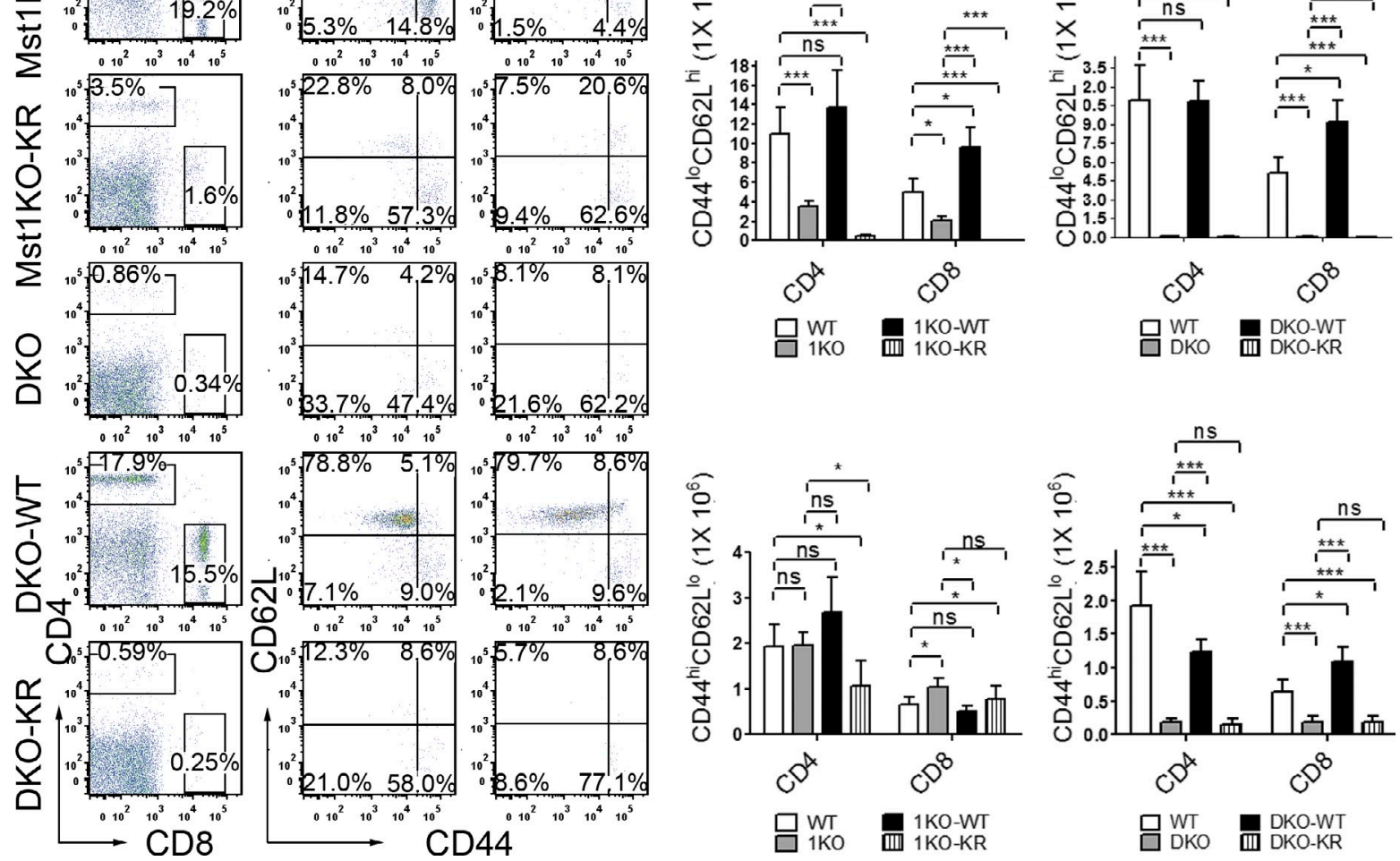
Similarly, elimination of Mst1 and Mst2 did not alter the abundance of Klf2, a transcriptional target of FoxO1/3 and itself a transcriptional regulator of CD62L, S1pr1 (S1P receptor 1), CCR7, and other genes relevant to T cell migration (Fig. 3 B).

The morphology of the Mst1/Mst2vavDKO thymus is subtly altered from normal; the distinctively darker staining of the cortex as compared with the medulla in the WT thymus, which reflects the greater number and density of cortical T cells as well as their lesser cytoplasmic content (Pearse, 2006), was considerably attenuated (Fig. 3 C), and staining for CD4 confirmed that the marked difference in cellular abundance/density between the cortex and medulla seen in the WT was also attenuated in the Mst1/Mst2vavDKO thymus. This alteration in thymic architecture differs from the acute effect of FTY720, a superagonist that down-regulates S1pr1, whose inhibition of thymic egress is accompanied by a thinning of the cortex and a marked expansion of the medulla (Yagi et al., 2000). Thus, the geographic distribution of $\mathrm{CD}^{+}$(SP and DP) cells appears to be abnormal in the Mst1/Mst2vavDKO thymus.

\section{Mst1/Mst2-deficient SP thymocytes resemble recent thymic emigrants in WT mice}

We next examined the developmental profile of the Mst1/ Mst2vavDKO thymocytes. Qa-2 is a nonpolymorphic MHC class 1 type molecule expressed late in thymocyte development whose abundance increases further after emigration, whereas CD24 is highly expressed throughout thymocyte development but is greatly diminished on recent thymic emigrants and diminishes further in the periphery (Boursalian et al., 2004). Inhibition of thymic egress with FTY720 increased the fraction of $\mathrm{CD} 4^{+} \mathrm{SP} \mathrm{Qa}-2^{\text {hi }} \mathrm{CD} 24^{\text {lo }}$ thymocytes from 27.9 to $60.9 \%$ (Fig. 4 A, top) and their total number from $\sim 2 \times 10^{6}$ to $\sim 5.7 \times 10^{6}$ (Fig. $4 \mathrm{~A}$, left bar graph), reflecting the continued intrathymic maturation of the $\mathrm{CD}^{+} \mathrm{SP}$ cells despite the blockade of egress. In the Mst1/Mst2vavDKO thymus, a very similar increase occurred in the percentage (Fig. 4 A, top) and number (Fig. 4 A, bar graphs) of $\mathrm{CD}^{+}$ and $\mathrm{CD}^{+} \mathrm{SP}$ cells that exhibited a Qa-2 ${ }^{\text {hi }} \mathrm{CD} 24^{\text {lo }}$ phenotype as compared with that seen with FTY720 treatment of WT mice. The S1P receptor subtype S1pr1, which is expressed very late in thymocyte development (Carlson et al., 2006), was detectable on $13.9 \%$ of Qa- $2{ }^{\text {hi }} \mathrm{CD} 24^{\mathrm{lo}} \mathrm{CD} 4^{+}$and $2.3 \%$ of $\mathrm{Qa}-2{ }^{\mathrm{hi}} \mathrm{CD} 24^{\mathrm{lo}} \mathrm{CD} 8^{+} \mathrm{SP}$ WT thymocytes, whereas in the Mst1/Mst2vavDKO thymus, the fraction of Qa- $2^{\text {hi }} \mathrm{CD} 24^{\text {lo }} \mathrm{CD} 4^{+}$ and $\mathrm{Qa}-2^{\text {hi }} \mathrm{CD} 24^{\mathrm{lo}} \mathrm{CD} 8^{+} \mathrm{SP}$ cells expressing S1pr1 was increased to $44.3 \%$ and $26.3 \%$, respectively (Fig. $4 \mathrm{~A}$, bottom). This increase in S1pr1 surface expression was paralleled by an increased level of S1pr1 messenger RNA in the thymus of Mst1-null and Mst1/Mst2vavDKO mice (Fig. 4 B). S1pr1 surface expression was severely reduced by pretreatment of both WT (Fig. 4, A and C) and Mst1/Mst2vavDKO mice with FTY720 (Fig. 4 C).

In addition to the increased numbers of SP thymocytes expressing S1pr1 and Qa-2, other indicators of the hypermaturation of $\mathrm{CD}^{+} \mathrm{SP}$ Mst1/Mst2vavDKO thymocytes were their higher levels of Qa-2 as well as CD62L expression and the substantial reduction in CD69 and CD24 expression (Fig. $4 \mathrm{D}$ ). The similarity of the hypermaturation phenotype of Mst1/Mst2vavDKO SP thymocytes to that elicited by FTY720 treatment of WT mice impelled us to measure S1P levels (Sensken et al., 2010), which we found to be similar in plasma (range 2.03-3.96 $\mu \mathrm{M}$ ) and thymic extracts (range 0.0-0.5 $\mathrm{pmol} / \mu \mathrm{g}$ protein) of WT and Mst1/Mst2vavDKO mice. In addition, the Mst1/Mst2vavDKO SP thymocytes exhibited no significant change from WT in their expression of the chemokine receptors CCR7, CXCR3, CXCR4, and CCR5, as well as the integrins CD11b and LFA-1 (Fig. 4 D). Thus, the DKO thymocytes exhibit uninterrupted maturation toward the phenotype of mature naive peripheral $\mathrm{T}$ cells, similar to that seen with WT thymocytes whose thymic egress is blocked selectively by down-regulation of the S1P receptor. The few peripheral $\mathrm{CD}^{+} \mathrm{T}$ cells in the Mst1/ Mst2vavDKO mice exhibited a CD62L ${ }^{\text {lo }} \mathrm{CD} 44^{\text {hi }}$ phenotype, without elevated expression of the activation markers CD69 or CD25 (Fig. 4 E).

\section{Thymic egress and LN entry of Mst1/Mst2-deficient SP thymocytes are severely reduced}

The Mst1/Mst2vavDKO mice experience a very high rate of infection, suggesting functional deficits in myeloid lineages in addition to $\mathrm{T}$ cells. To avoid confounding interactions and in view of the relatively well preserved developmental profile of thymic SP T cells in the Mst1/Mst2vavDKO mice, we crossed the Mst1-null/Mst2 ${ }^{\mathrm{ff}}$ mice with mice expressing Cre driven by the distal promoter of the Lck gene, which is expressed at a later stage of development (Zhang et al., 2005). As with the Mst1/Mst2vavDKO mice, the 1ck-cre/Mst1null/Mst $2^{\mathrm{ff}}$ (henceforth called Mst1/Mst2lckDKO) mice exhibited a dramatic reduction in peripheral $\mathrm{T}$ cells (Fig. $5 \mathrm{~A}$ ) and distortion of thymic architecture (Fig. 5 B); however, the number of $\mathrm{CD}^{+}$and $\mathrm{CD}^{+} \mathrm{SP}$ cells in the Mst1/Mst2lckDKO thymus was significantly increased (Fig. 5 A, top bar graph).

Figure 2. Mst1 WT and Mst1(KR) transgenic mice. (A) Flag-Mst1(WT) and Flag-Mst1 KR (inactive mutant K59R) expression driven by CD2 promoter was confirmed by Western blot of thymic extracts as in Fig. 1. (B) Representative flow cytometric analyses of spleen from Mst1 $1^{+/+}$Mst2 ${ }^{+/+}$(WT), Mst1-null (1KO), Mst1-nul//Flag-Mst1(WT) (1KO-WT), Mst1-null/Flag-Mst1(KR) (1KO-KR), Vav-Cre+Mst1-1-Mst2ff (DKO), Vav-Cre+Mst1-1-Mst2ff/Flag-Mst1(WT) (DKO-WT), and Vav-Cre ${ }^{+}$Mst1-1-Mst2f/Mst1(KR) (DKO-KR) mice for CD4+ and CD8 ${ }^{+}$T cells and their expression level of CD62L and CD44. (C) Total number of total $\mathrm{CD} 4^{+}$and $\mathrm{CD} 8^{+}$cells (top), $\mathrm{CD} 44^{\circ} \mathrm{CD} 62 \mathrm{~L}^{\text {hi }}$ (middle), and CD44 ${ }^{\text {hi }} \mathrm{CD} 62 \mathrm{~L}^{\text {lo }}$ (bottom) in spleen of WT and the various mutant transgenic mice. Comparisons used the Student's $t$ test $\left({ }^{*}, \mathrm{P}<0.05 ;{ }^{* *}, \mathrm{P}<0.01{ }^{* * *}, \mathrm{P}<0.001\right)$. Each bar represents combined results from three mice of the indicated genotype. Error bars indicate \pm SEM. 
A

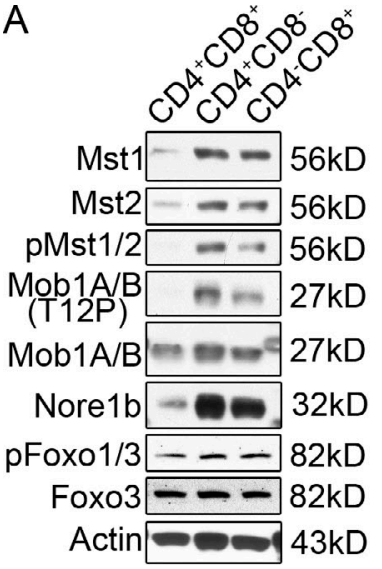

C
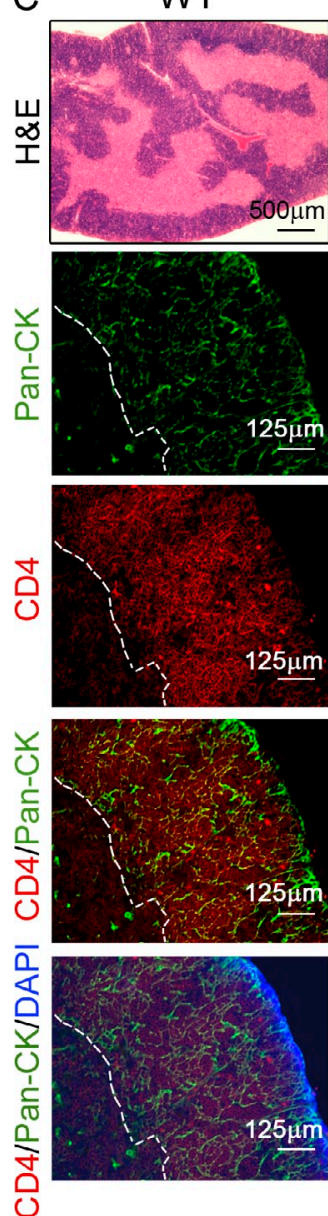
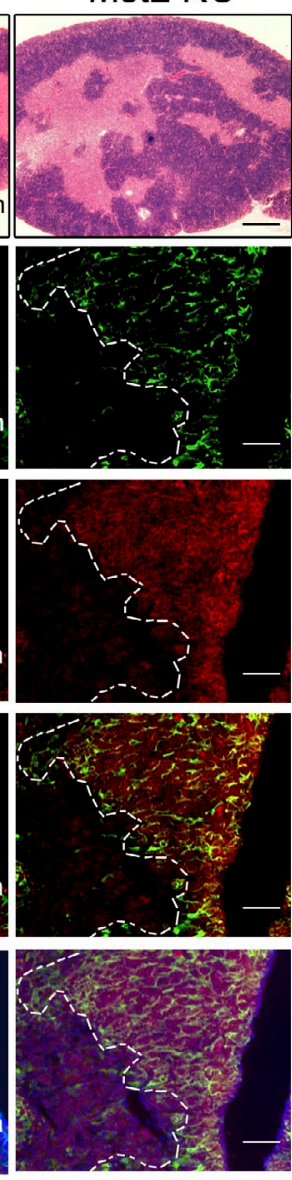

B

Mst2 KO

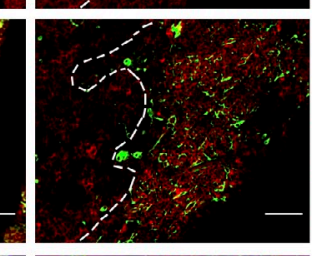

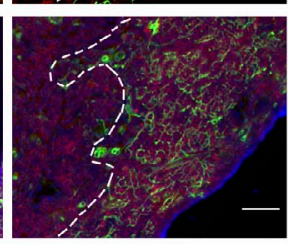

Mst1 KO
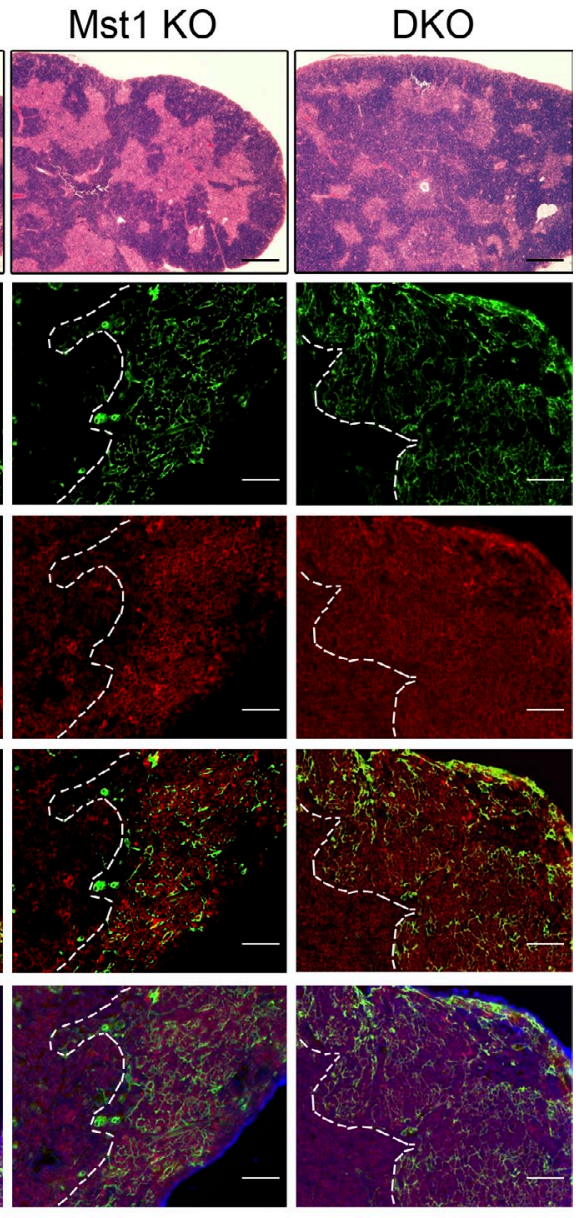

$56 \mathrm{kD}$

$56 \mathrm{kD}$

$37 \mathrm{kD}$

$27 \mathrm{kD}$

$43 \mathrm{kD}$

by $\sim 90 \%$ in the Mst1/Mst2lckDKO mice, demonstrating the substantial further reduction engendered by further elimination of Mst2 (Fig. 5 C). Although defective thymic egress was the dominant contributor to the low number of peripheral Mst1/Mst2lckDKO T cells, a second factor was their high rate of apoptosis, which in freshly isolated Mst1/Mst2lckDKO SP thymocytes was approximately sevenfold higher than in WT SP thymocytes; higher apoptosis was also evident in the Mst1/ Mst2lckDKO DP thymocytes (Fig. 5 D). As to the mechanisms responsible, because the Mst1/Mst2lckDKO thymocytes (like Mst1-null naive T cells; Zhou et al., 2008) showed a marked hyperproliferation in vitro in response to anti-CD3 (not depicted), we suspected that such a response might entrain an apoptotic outcome in vivo. Nevertheless, labeling in vivo with BrdU (Lucas et al., 1993) revealed no differences in the rate of intrathymic proliferation between WT and Mst1/ Mst2lckDKO thymocytes (Fig. 5 E), leaving the mechanism underlying their exaggerated apoptosis unresolved.

In addition to their defective thymic egress, Mst1/Mst2deficient SP T cells were also incapable of entering SLOs when placed directly in the circulation. $24 \mathrm{~h}$ after i.v. injection of identical numbers of $\mathrm{CD}^{+} \mathrm{SP}$ thymocytes from WT and Mst1/Mst2vavDKO mice into WT recipients, only cells from the WT donor were present in peripheral LNs, whereas 80-90\% of the circulating donor T cells were from the Mst1/ Mst2vavDKO donor (Fig. 6 A, top). To assess the localization 
of the infused WT and Mst1/Mst2 DKO thymocytes residing in the spleen, in a separate experiment, we infused CD45.2 $2^{+}$WT/Lck-cre and Mst1/Mst2lckDKO SP thymocytes into CD 45.1 recipients. Spleens were removed $24 \mathrm{~h}$ later and stained with anti-CD45.2 and anti-B220 (the latter to define white pulp), and the number of CD45.2 $2^{+}$cells in white pulp and in similar sized areas of red pulp was counted (a total of $\sim 1,500$ cells of each genotype). The percentage of total Mst1/Mst2 DKO CD45.2 ${ }^{+}$cells within the CD45.1 ${ }^{+}$ recipient splenic follicles was diminished by $\sim 70 \%$ as compared with the WT CD $45.2^{+}$donors (Fig. 6 D). Thus, the Mst1/Mst2 DKO SP thymocytes are greatly deficient in their ability to enter splenic white pulp. Cell loss, probably caused by apoptosis, was a second factor contributing to low number of Mst1/Mst2lckDKO SP thymocytes recovered after i.v. injection. By $1 \mathrm{~h}$ after i.v. infusion, the fractional recovery of infused Mst1/Mst2lckDKO SP thymocytes from blood and SLOs was only about half that of WT or Mst1-null SP thymocytes, which were comparable (Fig. 6 E). The ability of Mst1-null SP thymocytes to enter LNs was also inferior to that of WT cells (Fig. $6 \mathrm{~B}$ ) but markedly superior to that of the Mst1/Mst2vavDKO SP thymocytes (Fig. 6 C). Thus, despite normal or enhanced expression of the major receptors that govern thymic egress (i.e., S1pr1) and entry into SLOs (CCR7), T cells deficient in Mst1 and Mst2 are almost entirely unable egress the thymus or enter SLOs.

\section{Deficiency of Mst1 and Mst2 disables S1P and chemokine-induced chemotaxis, actin polarization, and activation of rho family GTPases in SP thymocytes}

Emigration of SP thymocytes to the periphery requires the ability to migrate in response to the much higher level of S1P in blood (Drennan et al., 2009). The migration in vitro of WT $\mathrm{CD}^{+}$and $\mathrm{CD}^{+}$thymocytes toward $\mathrm{S} 1 \mathrm{P}$ at 10 and $100 \mathrm{nM}$ increased progressively, but at $1 \mu \mathrm{M}, \mathrm{S} 1 \mathrm{P}$ did not differ from baseline levels, likely reflecting down-regulation of the receptor S1pr1 (Fig. 7 A); a similar desensitization occurred with S1P-stimulated Mob1A/B phosphorylation (Fig. 7 B). Compared with WT thymocytes, migration toward S1P was unaltered in Mst2-null thymocytes, slightly diminished in Mst1-null thymocytes, but virtually eliminated in the Mst1/ Mst2vavDKO SP thymocytes (Fig. 7 A). The loss of the chemotactic migratory response in the Mst1/Mst2vavDKO thymocytes was not restricted to $\mathrm{S} 1 \mathrm{P}$; the migratory response to CCL19 and CCL21, which in the Mst1-null SP thymocytes was reduced by approximately half, in the Mst1/Mst2vavDKO cells was, like the response to S1P, also lost completely (Fig. 7 C). The inability of these stimuli to elicit a migratory response from Mst1/Mst2vavDKO thymocytes was accompanied by the failure of S1P and CCL19 to promote actin polarization (Fig. 7 D).

Regulation of the actin cytoskeleton is critically dependent on the localized activation of rho family GTPases (Gomez and Billadeau, 2008; Tybulewicz and Henderson, 2009; Ward and Marelli-Berg, 2009). CCL19, for example, elicited a transient increase in rac1 GTP charging in WT $\mathrm{CD} 4^{+} \mathrm{SP}$ thymocytes that peaked at $2-5 \mathrm{~min}$ (Fig. $8 \mathrm{~A}$ ) and returned toward baseline by $10 \mathrm{~min}$ (not depicted); this response was substantially reduced in Mst1-null thymocytes and lost entirely in the Mst1/Mst2vavDKO thymocytes (Fig. 8 A). We surveyed a variety of other ligands for their ability to promote rac1 GTP charging in thymocytes; in addition to CCL19, substantial increases in rac1 GTP charging were also seen in response to CCL21, CCL17, and SDF1 and more modestly with CCL25. None of these ligands promoted rac1 GTP charging in the Mst1/Mst2vavDKO CD4 ${ }^{+}$SP thymocytes (Fig. 8 B). We did not detect an increase in rac1 GTP charging in response to $\mathrm{S} 1 \mathrm{P}$ (Fig. $8 \mathrm{~B}$ ) but did observe a robust S1P-induced increase in rhoA GTP charging (Fig. $8 \mathrm{C}$ ), as previously reported (Stam et al., 1998); this response was reduced in the Mst1-null thymocytes and entirely absent in Mst1/Mst2vavDKO thymocytes. Thus, elimination of Mst1 and Mst2 disables the ability of S1P and a variety of chemokine receptors to activate GTP charging of rac1 and rhoA. The ability of these ligands to promote Mob1A/B phosphorylation, a reflection of Mst1/Mst2 activation, was lost in parallel (Fig. 8 D). Notably, these ligands did not promote the phosphorylation of Foxo1/3 (Fig. 8 E) or Lats1/2 (Fig. 8 F, left) at sites known to be phosphorylated by Mst1 or Mst2, nor was the phosphorylation of FoxO1/3 (Fig. 8 E) and Lats1/2 (Fig. 8 F) in thymocytes altered by deletion of Mst1 and Mst2. Finally, the ability of CCL19 and SDF-1 to activate p44Erk and p38 (Fig. 8 E) and the ability of $\mathrm{H}_{2} \mathrm{O}_{2}$ to stimulate Lats1/2 phosphorylation (Fig. $8 \mathrm{~F}$, right) was similar in WT and Mst1/Mst2-deficient CD 90.2 $2^{+}$thymocytes.

\section{Mob1A/B phosphorylated by Mst1 or Mst2 binds and activates the Dock8 rac1 guanyl nucleotide exchange factor (GEF)}

The marked deficits in the ability of several chemokines and S1P to activate rac1 and rhoA, respectively, to polarize the actin cytoskeleton, and to promote the migration in vitro of Mst1/Mst2-deficient SP thymocytes certainly contribute to the inability of these cells to emigrate to the thymus in vivo and, once in the circulation, to enter LNs. It is highly likely, based on the ability of WT but not kinase-inactive Mst1 to correct these abnormalities, that these deficits arise from the failure of phosphorylation of one or more Mst1/Mst2 polypeptide substrates. As shown above (Fig. 8, E and F), deletion of Mst1 and Mst2 eliminates thymocyte Mob1A/B phosphorylation without affecting Lats1/2 or FoxO1/3 phosphorylation. Consequently, we focused on Mob1A/B, seeking proteins that, like Lats1/2 and ndr1/2, associate with the noncatalytic Mob1A/B polypeptides in a phosphorylationdependent manner. Overexpression of Mob1B in 293 T cells retrieved endogenous Lats1, ndr2 (both known physiological partners of Mob1), and equal amounts of Dock6 and Dock7, rho family GEFs (Meller et al., 2005; Côté and Vuori, 2007). 11 members of the Dock family of GEFs occur in mouse and man, divided into four subfamilies (A-D) based on amino acid sequence alignment; Dock6, Dock7, and Dock8 form subfamily C. All Dock proteins are $\sim 200 \mathrm{kD}$ and contain 
A

CD4 SP
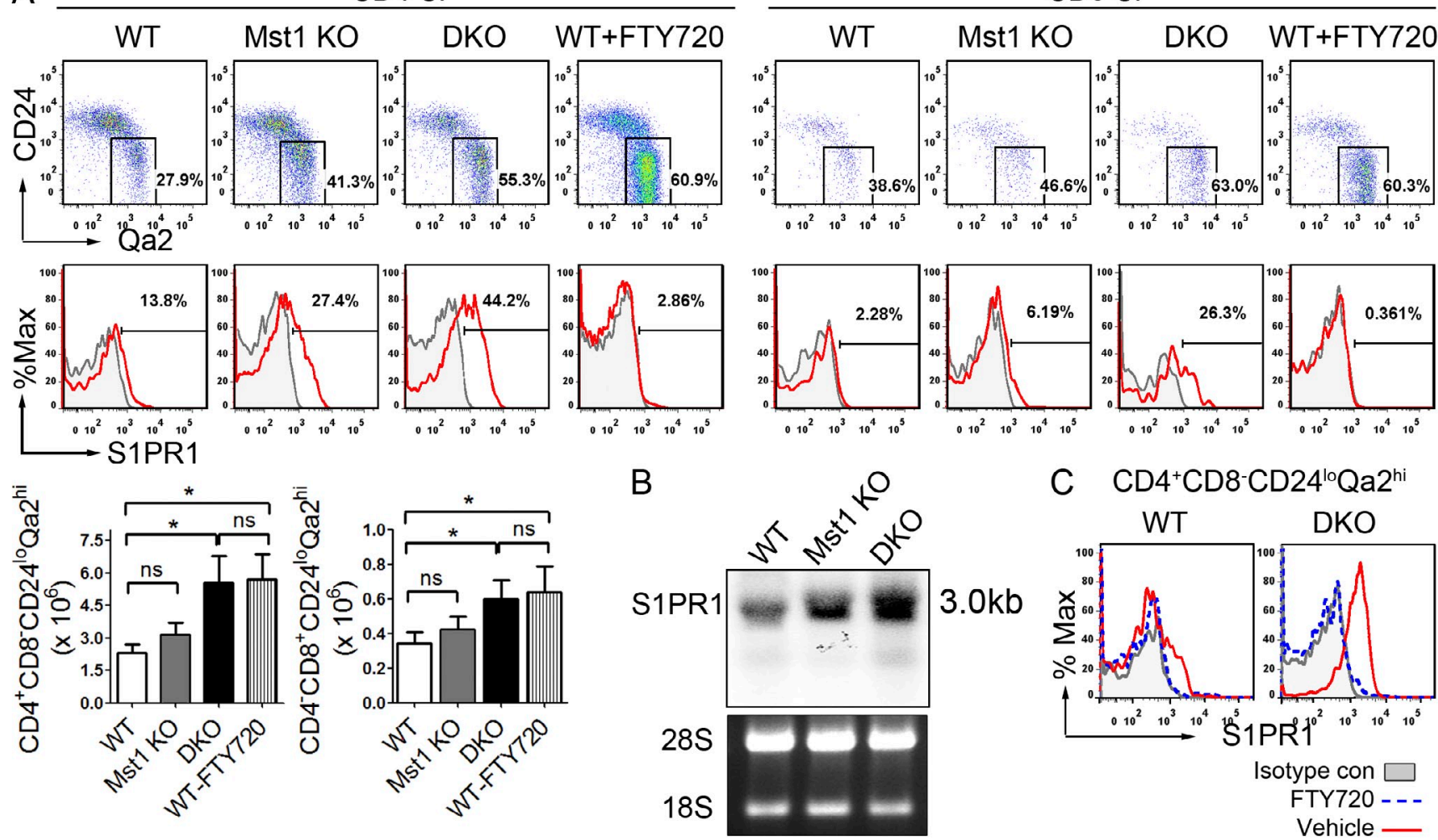

D

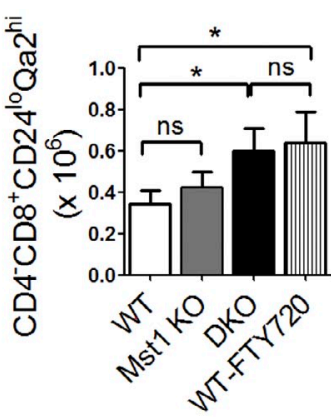

Thymus

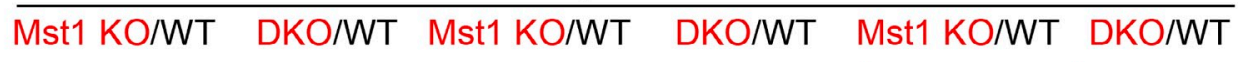

C $\mathrm{CD}^{+} \mathrm{CD} 8{ }^{-\mathrm{CD}} 24^{\mathrm{lo}} \mathrm{Qa} 2^{\mathrm{hi}}$

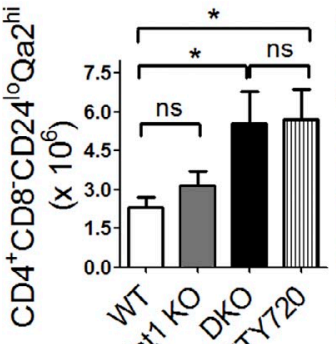
可
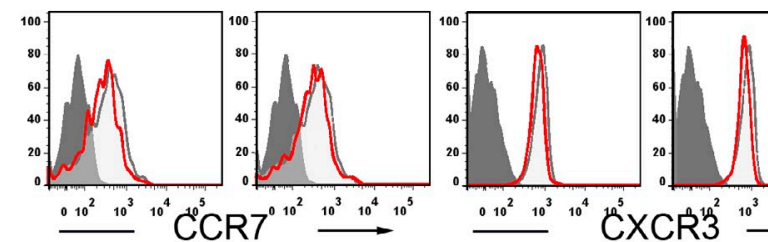

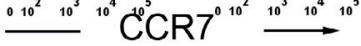
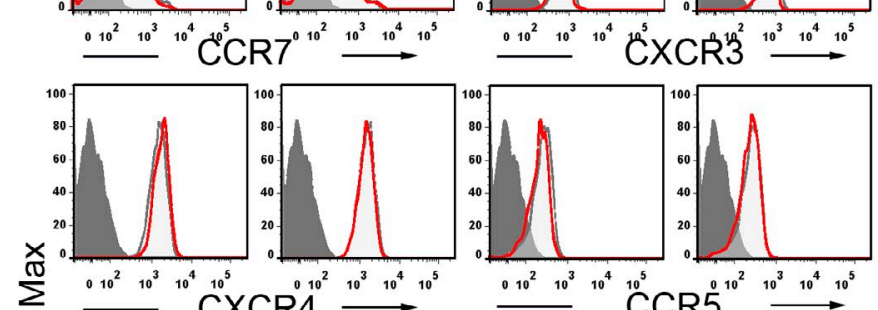

๙ீ
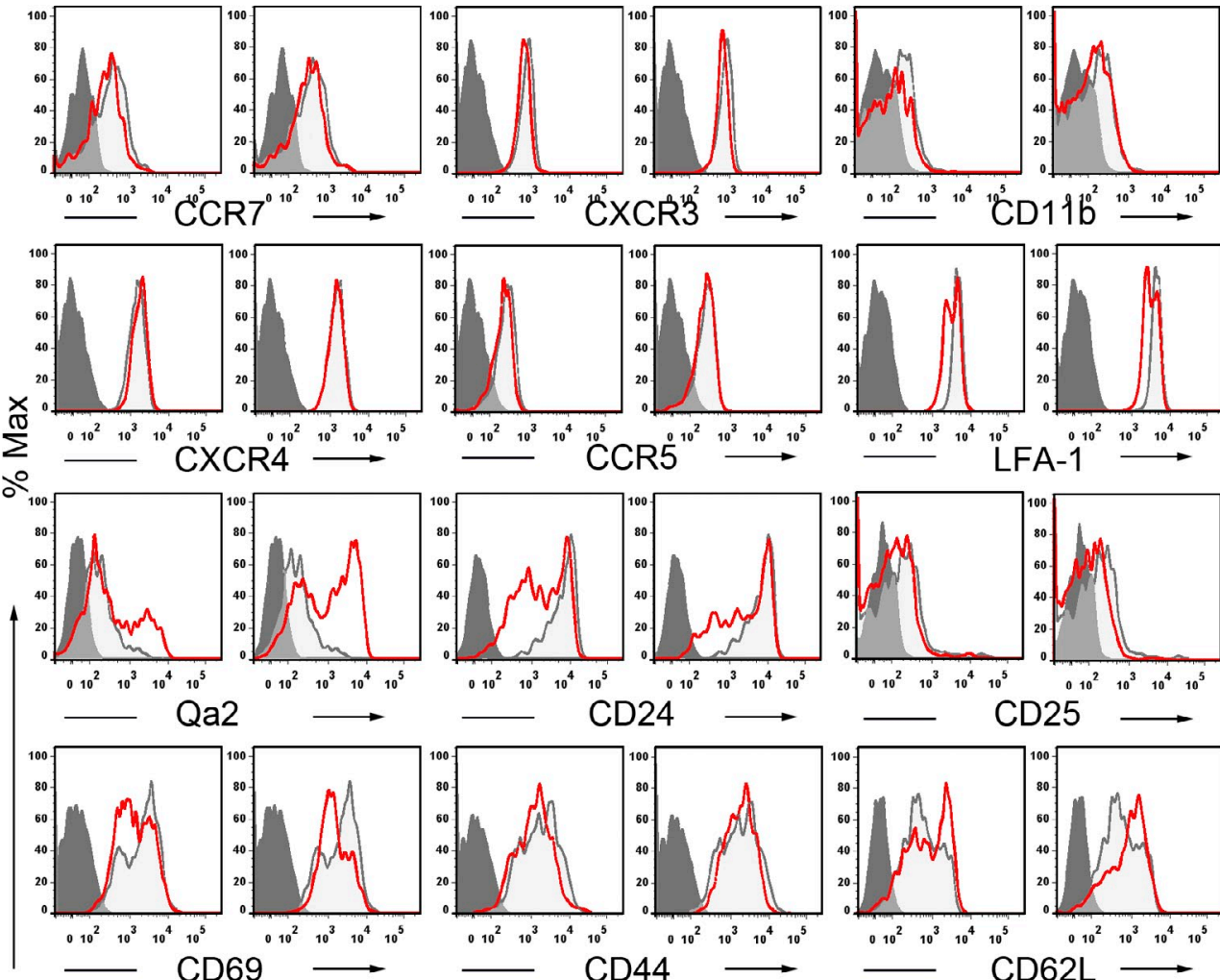

$010^{2} 10^{3} 10^{4} \quad C^{5} D 11 b^{6^{2}} \stackrel{1^{3} 10^{4} 10^{5}}{\longrightarrow}$
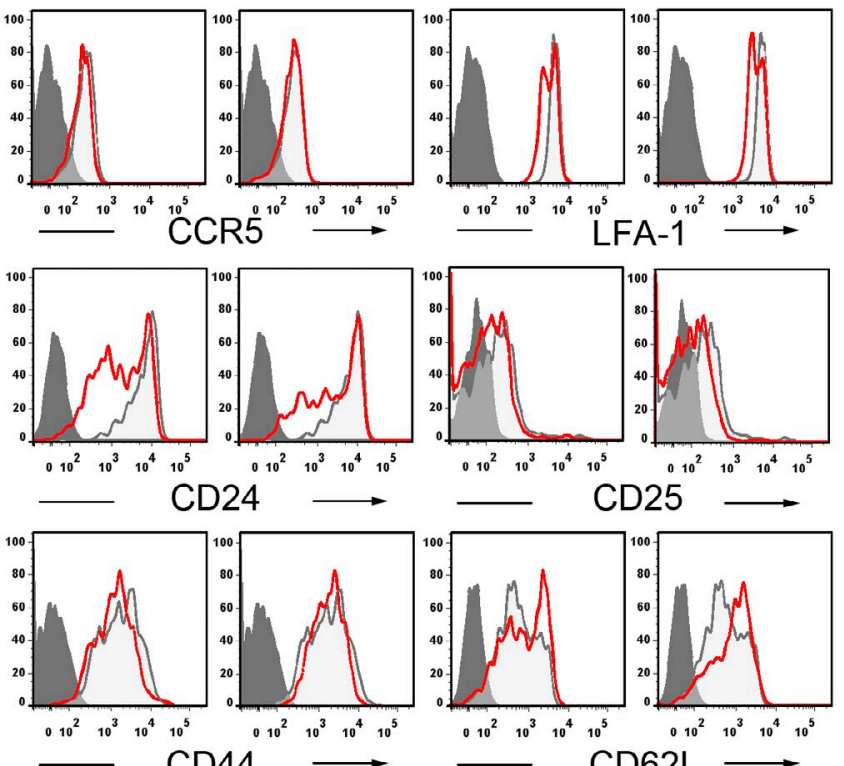

E

Mst1 KO/WT DKO/WT
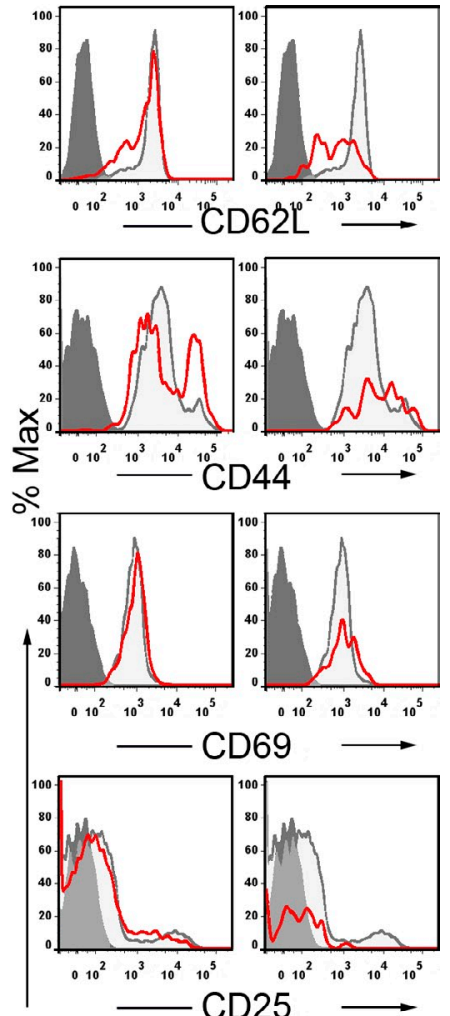
two conserved domains, the DHR1/CZH1 domain in the amino-terminal half of the protein, a C2 type phospholipidbinding domain thought to contribute to membrane localization, and DHR2 (approximately 1695-2068 aa), which contains the nucleotide exchange domain, located near the protein carboxy terminus. Neither Dock6 nor Dock7 is expressed in lymphoid tissues; however, Dock 8 is highly expressed in thymus (Tybulewicz and Henderson, 2009), and recombinant Dock8 also binds preferentially to phosphorylated Mob1 (Fig. 9 A, left). Notably, Dock2, a member of Dock subfamily B whose functions in $\mathrm{T}$ cells have been extensively characterized (Reif and Cyster, 2002), did not coprecipitate with Mob1B in the presence or absence of okadaic acid (OKA; Fig. 9 A, right). We next examined whether Dock8 endogenous to $\mathrm{T}$ cells interacts with Mob1A/B in an Mst1/Mst2-dependent manner. CD90.2 $2^{+}$thymocytes were isolated from WT and Mst1/Mst2lckDKO mice and treated with CCL19 for $5 \mathrm{~min}$, and the Dock8 immunoprecipitate was immunoblotted for Mob1A/B (Fig. 9 B). CCL19 stimulated the phosphorylation of endogenous Mob1A/B and promoted the coprecipitation of Mob1A/B with Dock8 in WT but not in Mst1/Mst2lckDKO thymocytes.

Available antibodies do not enable immunoprecipitation of Mob1A/B; we therefore created transgenic mice expressing Flag-Mob1B and mutated Flag-Mob1B[Thr12Ala/Thr35Ala] driven by the human CD2 promoter (de Boer et al., 2003). Expression of recombinant Flag-Mob1B WT in thymus proved to be far below the level of endogenous Mob1A/B; nevertheless, a substantial amount of endogenous Dock8 was recovered with Flag-Mob1B and in slightly greater amounts from the extract of CCL19-treated cells (Fig. 9 C), whereas Dock8 did not coprecipitate with Flag-Mob1B[Thr12Ala/ Thr35Ala]. A further indication of the ability of a Mob1B to bind Dock8 in the cell was provided by using a membranebound Mob1B, created by fusing the $\mathrm{c}-\mathrm{Src}$ amino-terminal myristoylation motif to the Flag-Mob1B amino terminus. The transiently expressed myr-Flag-Mob1B polypeptide was extensively membrane localized (Fig. 9 D, third column), as was myr-Flag-Mob1B[Thr12Ala/Thr35Ala]. Myr-Flag-Mob1B exhibited a marked increase in phosphorylation at the sites catalyzed specifically by Mst1/Mst2, as compared with (nonmyristolylated) Flag-Mob1B (Fig. 9 D, immunoblot); the latter was diffusely cytoplasmic (Fig. 9 D, second column). Recombinant Dock8, which exhibits a diffuse distribution during transient expression, showed a modest colocalization with Flag-Mob1B but was extensively colocalized with myr-Flag-Mob1B WT but exhibited no colocalization with myr-Mob1B[Thr12Ala/Thr35Ala] (Fig. 9 D).

We next examined the functional consequence of Mob1B binding to Dock8. Mob1B and full-length Dock8 were coexpressed with rac1 in 293 cells (which lacked Dock8 but expressed Dock6 and Dock7), and the extent of rac1 GTP charging was estimated by pull-down of rac1 from cell extracts with the CRIB domain of the PAK1 protein kinase, which binds rac1 and cdc42 preferentially when GTP charged (Thompson et al., 1998). If endogenous Mob1A/B was depleted using RNA interference directed to their 3' untranslated regions, the expression of recombinant Flag-Mob1B alone caused a modest increase in rac1 pull-down, likely reflecting the interaction of Flag-Mob1B with endogenous Dock6/7. Expression of recombinant Dock8 alone also gave a modest increase in rac1 pull-down, but coexpression of Flag-Mob1B with Dock8 increased rac1 pull-down further as compared with vector controls and either alone (Fig. 9 E). Thus, the binding of Mob1B to Dock8, which requires Mob1B phosphorylation, stimulates the Dock8 GEF activity toward rac1.

\section{DISCUSSION}

Whereas deletion of Mst2 from the lymphoid compartment has no evident effect, the additional deficiency of Mst2 on an Mst1-null background causes a marked exacerbation of the deficits seen in Mst1-null T cells. Thymocyte development appears to proceed normally, probably because of the very low abundance and activity of these kinases in DP and developmentally earlier thymocytes. Nevertheless, the ability of SP thymocytes to exit to the circulation, modestly impaired in the Mst1-null mouse, is severely inhibited in the Mst1/Mst2 DKO. As with thymocyte egress, the entry of $\mathrm{T}$ cells into LNs, which is also moderately impaired in Mst1-null cells, is lost entirely in the Mst1/Mst2-deficient SP thymocytes. These deficits in the migration of Mst1/Mst2-deficient SP thymocytes occur despite normal levels of the integrin LFA-1, of the S1P receptor S1 pr1, and of multiple chemokine receptors. Rather, the migratory deficits are in large part caused by the failure of these receptors to promote the activation of rho family GTPases and polarization of the actin cytoskeleton in the thymocytes; based on the phenotype of Mst1-deficient naive T cells (Katagiri et al., 2006; Zhou et al., 2008, 2009), integrin clustering and activation are also likely to be abrogated.

\footnotetext{
Figure 4. Flow cytometric analysis of $\mathrm{CD}^{+} / \mathrm{CD}^{-}$(CD4SP) and CD4-/CD8 ${ }^{+}$(CD8SP) thymocytes and peripheral T cells from WT, Mst1 K0, and Mst1/Mst2vavDKO mice. (A) The expression of S1pr 1 was quantified on the CD24\%/Oa- $2^{\text {hi }}$ fraction of CD $4^{+} / \mathrm{CD}^{-}{ }^{-}$and $\mathrm{CD} 4^{-} / \mathrm{CD}^{+}$thymocytes from WT, Mst1 KO, and Mst1/Mst2vavDKO, and WT mice treated with an i.p. injection of either PBS or $10 \mathrm{mg} / \mathrm{kg}$ FTY720 $24 \mathrm{~h}$ prior. The bar graphs show the absolute number of $\mathrm{CD}^{+} / \mathrm{CD}^{-}$(left) and $\mathrm{CD} 4^{-} / \mathrm{CD} 8^{+}$(right) $\mathrm{CD} 24^{\circ} \mathrm{O} a-2^{\text {hi }}$ thymocytes. Each bar represents combined results from three mice of the indicated genotype $\left({ }^{*}, \mathrm{P}<0.05\right)$. Error bars indicate \pm SEM. (B) Northern blot of thymic S1pr1 messenger RNA. (C) The abundance of S1pr1 on CD4SPCD24/00a-2 ${ }^{\text {hi }}$ thymocytes from WT and Mst1/Mst2vavDKO mice was analyzed with or without a prior i.p. injection of FTY720 as in A. (D) CD4 $4^{+} / \mathrm{CD} 8^{-}$thymocytes from WT mice were compared with those from Mst1 KO or Mst1/Mst2vavDKO mice for the expression of the chemokine receptors, integrins, and developmental markers indicated. (E) The expression levels of the indicated markers on CD4+ cells from spleen of WT mice were compared with those from Mst1 K0 or Mst1/Mst2vavDKO mice. Representative profiles are shown.
} 


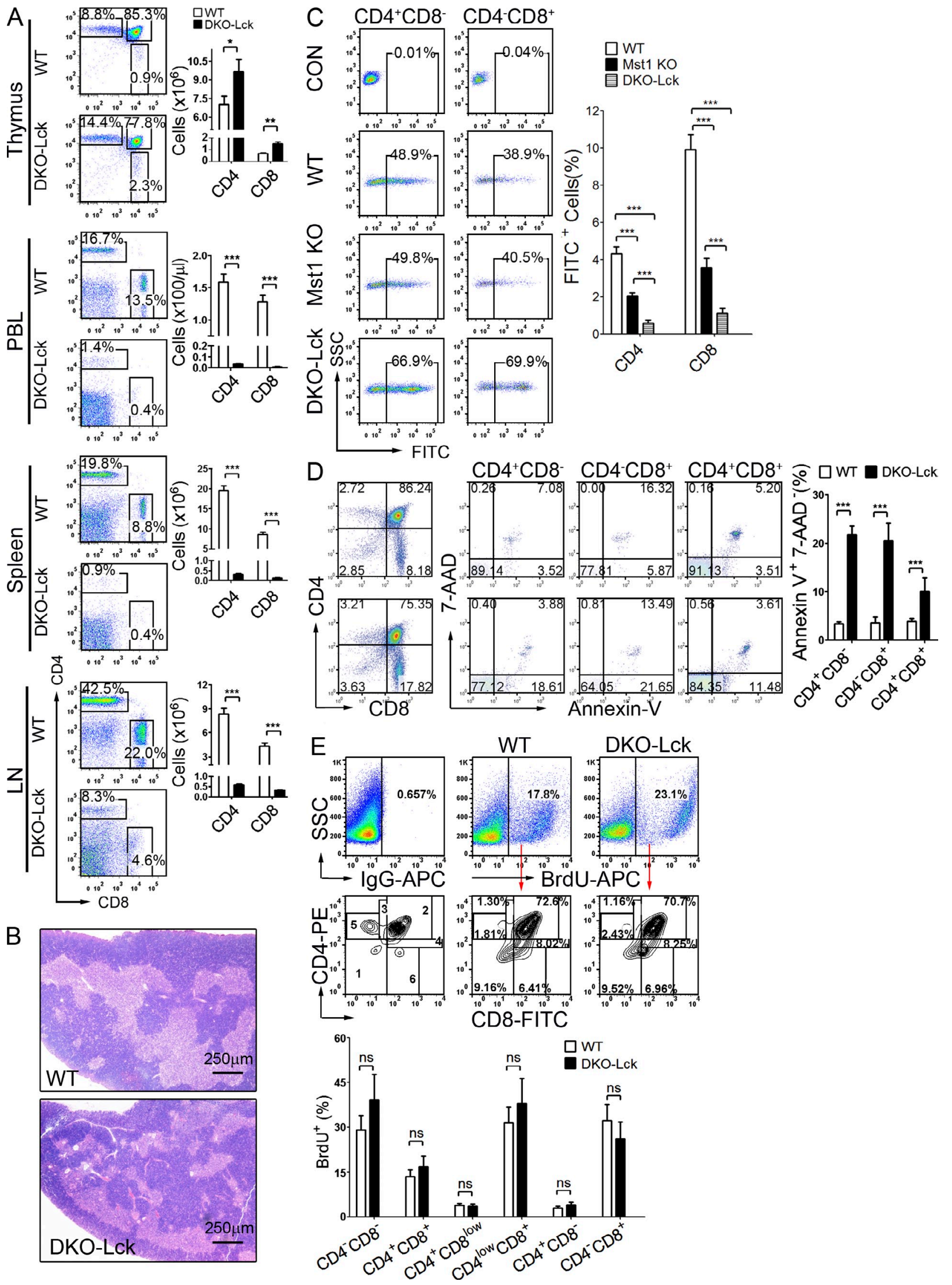


Thymocyte maturation is thought to depend in part on an orderly migration of the cells first into the cortex and then into the medulla, a migration orchestrated by the coordinated expression of chemokines and their receptors. The normal maturation of Mst1/Mst2-deficient thymocytes to a state resembling recent thymic emigrants found in normal mice suggests that chemokine regulation of rho GTPases and actin during thymocyte development through the DP stage occurs independently of Mst1/Mst2. Thus, among the various defects evident in the Mst1-null T cell compartment that contribute to the low levels of peripheral naive $\mathrm{T}$ cells (i.e., defective migration, hyperproliferation, and accelerated apoptosis), deficient migration emerges as the limiting defect with DKO of Mst1 and Mst2.

Nevertheless, the high rate of ongoing apoptosis of Mst1/ Mst2-deficient SP thymocytes (Fig. 5 D) is certainly an important contributor to the deficiency of peripheral $\mathrm{T}$ cells. The major factors responsible for the excessive apoptosis of the Mst1/Mst2-null $\mathrm{CD}^{+}{ }^{+}$thymocytes are not known, but candidates include their inappropriate entry into a proliferative program (Zhou et al., 2008), the activation of apoptosis by the high levels of reactive oxygen species (Choi et al., 2009), and perhaps some alteration in the components or regulation of intrinsic apoptotic pathways.

The correction of the phenotype of Mst1/Mst2 deficiency in the lymphoid compartment by transgenic expression of WT but not catalytically inactive Mst1 establishes that the defects in cell migration and rho GTPase regulation are caused by the lack of Mst1/Mst2-catalyzed substrate phosphorylation. The absolute dependence of Mob1A/B phosphorylation on Mst1/Mst2, in contrast to the minimal impact of Mst1 deletion on Lats1/2 (Fig. 8 F) in T cells (Zhou et al., 2008), impelled us to seek other Mst1/Mst2 substrates as well as other phosphorylation-dependent Mob1A/B binders. The Mob1A and Mob1B polypeptides are 96\% identical, highly conserved from yeast to Drosophila to mammals, and best known for their ability to bind to the Saccharomyces cerevisiae kinase Dbf2 and the Drosophila kinases Lats/Warts (orthologous to mammalian Lats1/2) and Trc (orthologous to mammalian ndr1/2); Mob1A or Mob1B binding promotes the autophosphorylation of these kinases on their activation loop, contributing thereby to their catalytic activation (Bichsel et al., 2004; Hergovich, 2011). We demonstrated that the ability of Mob1A/B to bind Lats1/2 and ndr1/2 is strongly dependent on Mob1A/B phosphorylation at Thr12 and Thr35 by Mst1 and/or Mst2 (Praskova et al., 2008). The identification of the Dock-C subfamily of guanyl nucleotide exchangers as phosphorylation-dependent Mob1A/B partners unveils a new signaling pathway downstream of Mst1/ Mst2 as well as a previously unrecognized mode of regulation of Dock-C family GEFs.

Thymocytes express multiple rac1/2 GEFs, including vav1-3, Dock1, Dock2, Dock5, and Dock8 (Tybulewicz and Henderson, 2009). The deficiencies in migration, actin polarization, and rac GTPase activation seen in the Mst1/ Mst2-deficient thymocytes resemble those seen with deletion of Dock2, a Dock-B subfamily rac1 GEF expressed largely in lymphoid tissues (Fukui et al., 2001). Dock2-null mice exhibit diminished numbers of $\mathrm{T}$ cells in the periphery. T lymphoid progenitor entry (Lei et al., 2009) and thymocyte development, apart from somewhat impaired positive and negative selection (Sanui et al., 2003b), are relatively well maintained in the absence of Dock2; however, egress of SP thymocytes from thymic organ culture in response to CCL19 is reduced by 95\% (Sanui et al., 2003a). In addition, entry of Dock2-deficient T cells into SLOs is defective (Fukui et al., 2001). Despite the presence of vav, Dock2-deficient $\mathrm{T}$ cells exhibit diminished chemokine activation of rac1 and greatly reduced actin polymerization (Fukui et al., 2001). As regards the regulation, Dock2 appears to require the noncatalytic protein ELMO1 for nucleotide exchange in cells (Sanui et al., 2003b). Recruitment by upstream regulators may occur through its aminoterminal SH3 domain, which binds Crk; the Dock2 DHR1 domain binds PtdIns3,4,5P3; however, sustained localization requires the generation and binding of phosphatidic acid to a polybasic region in the DHR2 segment (Nishikimi et al., 2009). Despite the overlaps in the properties of Dock2and Mst1/Mst2-deficient T cells, we have no evidence that Dock2 is regulated downstream of Mst1/Mst2. Moreover, the deficiency of peripheral T cells in the Mst1/Mst2 DKO is much greater than in Dock2-deficient mice or in thymocytes

Figure 5. Mst1/Mst2lckDKO mice have lymphopenia caused by impaired thymic egress. (A) Representative flow cytometric analyses for CD4 and CD4 and cell counts from thymus, blood, spleen, and LNs from Lck-Cre+Mst1+l+Mst2+l+ (WT) and Lck-Cre+Mst1 ${ }^{-l-M s t 2}{ }^{\text {ff }}$ (Mst1/Mst2lckDKO) mice. Each bar represents combined results from three mice of the indicated genotype $\left({ }^{*}, \mathrm{P}<0.05 ;{ }^{* *}, \mathrm{P}<0.01 i^{* * *}, \mathrm{P}<0.001\right)$. (B) Thymic morphology of Mst $1 /$ Mst2IckDKO mice; a representative section. (C) Egress of FITC-labeled thymocytes in vivo. $24 \mathrm{~h}$ after an intrathymic injection of FITC, the thymus, spleens, LNs, and peripheral blood from WT, Mst1 KO, and Mst1/Mst2lckDKO mice were analyzed by flow cytometry. The percentage of FITC-labeled CD4+ and $\mathrm{CD}^{+}$cells emigrating to the thymus was calculated as total number of FITC-labeled CD4+ or CD8 ${ }^{+}$cells in SLOs and blood divided by total (thymic + peripheral) FITC-labeled CD4+ or CD8 ${ }^{+}$cells from all sites, multiplied by 100 . Statistical analyses were performed using the Student's $t$ test $\left.{ }^{* * *}, P<0.001\right)$. Each bar represents combined results from three mice of the indicated genotype. (D) Ongoing apoptosis events in freshly isolated $C D 4^{+} / \mathrm{CD}^{+}{ }^{+}, \mathrm{CD}^{+} / \mathrm{CD}^{-}{ }^{-}$, and $C D 4^{-} / C D 8^{+}$thymocytes are estimated from Annexin $\mathrm{V}-\mathrm{FITC}$ and 7-AAD staining. The bar graph shows the percentage of Annexin $\mathrm{V}^{+} / 7-\mathrm{AAD}{ }^{-} \mathrm{SP}$ and DP thymocytes from three independent experiments $\left.{ }^{* * *}, P<0.001\right)$. (E) BrdU-labeled cells among the various subsets of thymocytes. Mice received two i.p. injections of BrdU at a 4-h interval. The thymus was removed for analysis $1 \mathrm{~h}$ after the second injection. Thymocytes were stained with antibodies against mouse CD4-PE, CD8-FITC, BrdU-APC, or isotype control IgG-APC. Regions defining six thymocyte subsets were defined, and the percentage of each subset in $\mathrm{BrdU}^{+}$cells is shown (middle). The percentage of $\mathrm{BrdU}^{+}$cells in each thymocyte subset is shown in the bar graph. Representative profiles are shown. Each bar represents combined results from three mice of the indicated genotype. (A and C-E) Error bars indicate \pm SEM. 
A
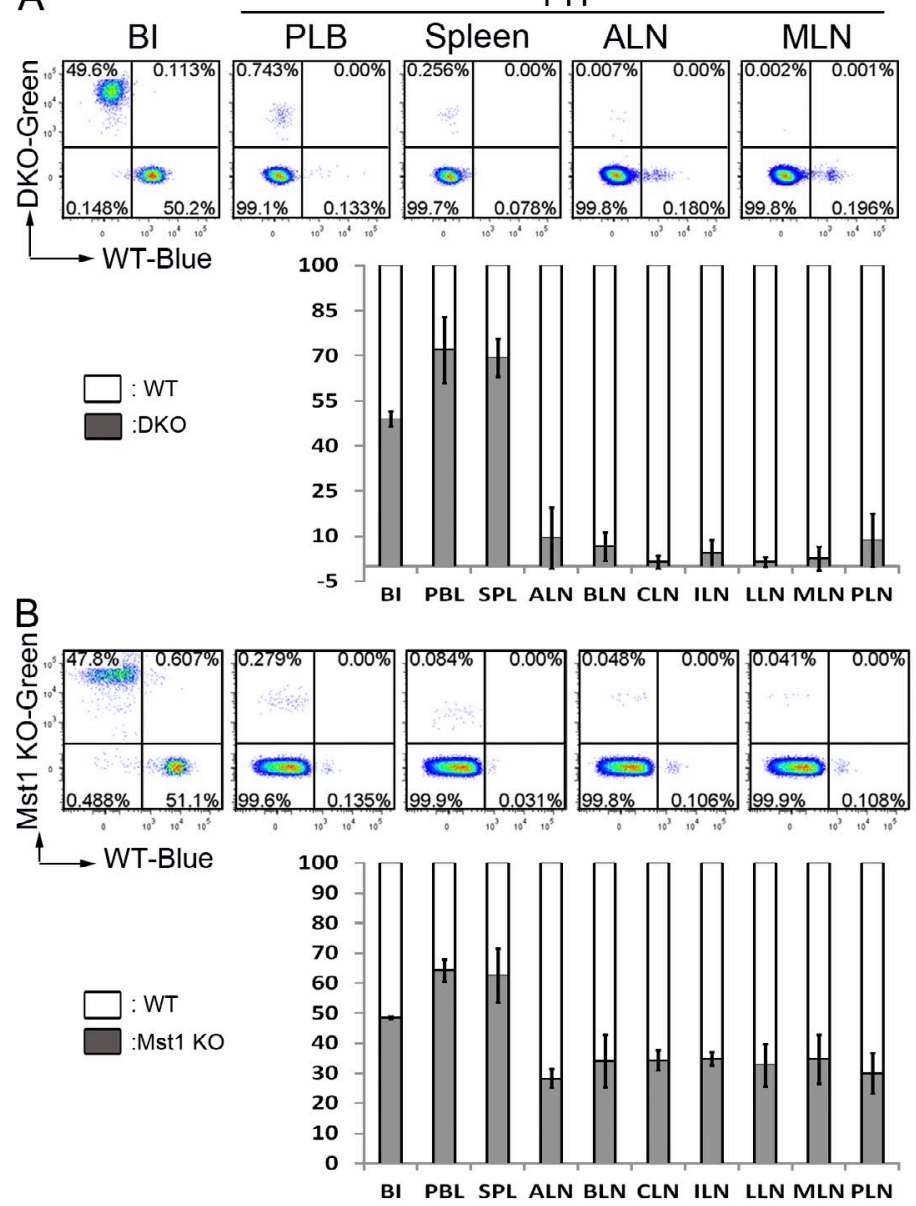

C

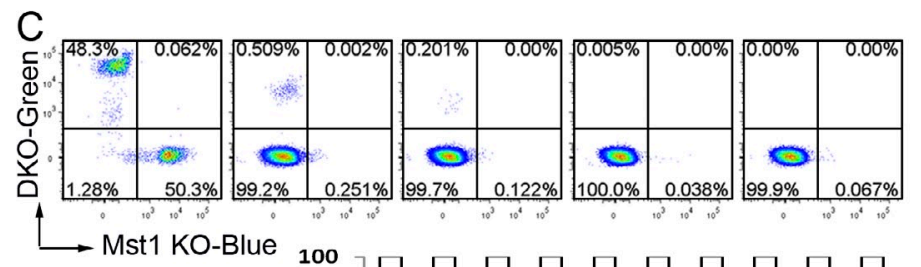

Mst1 KO-Blue
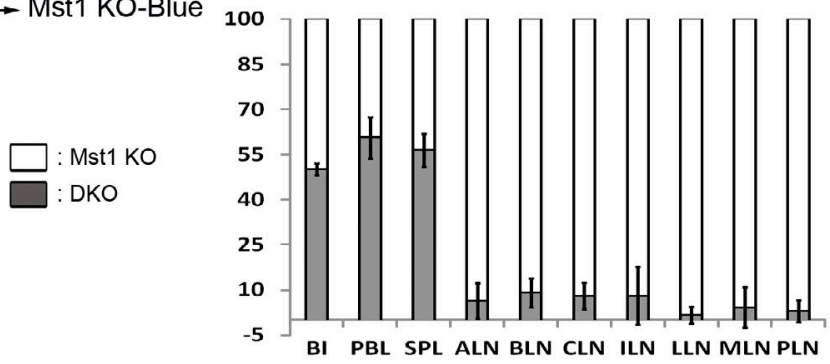

$24 \mathrm{H}$
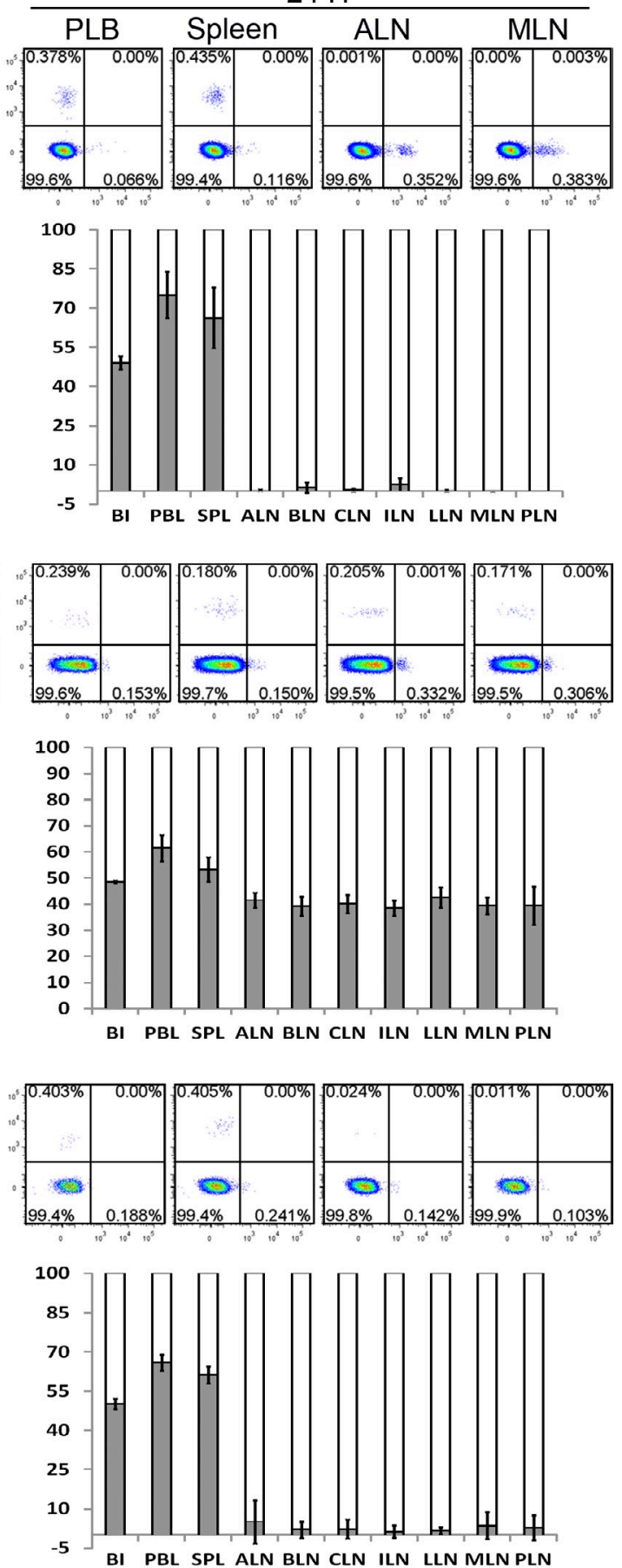
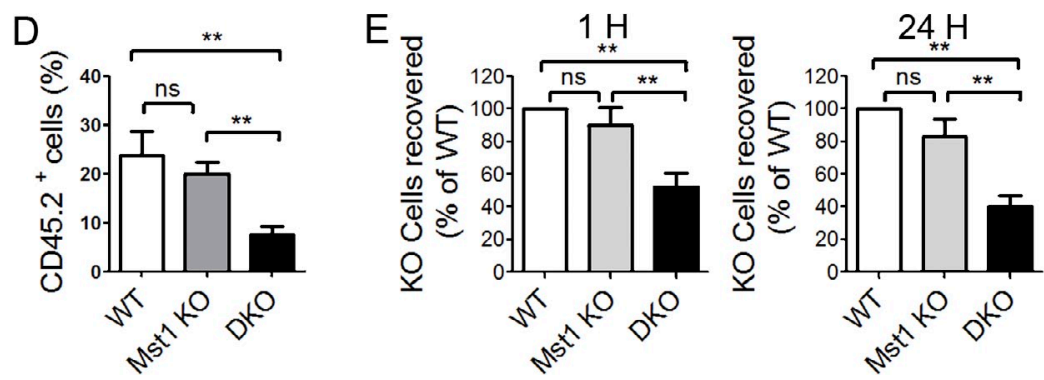

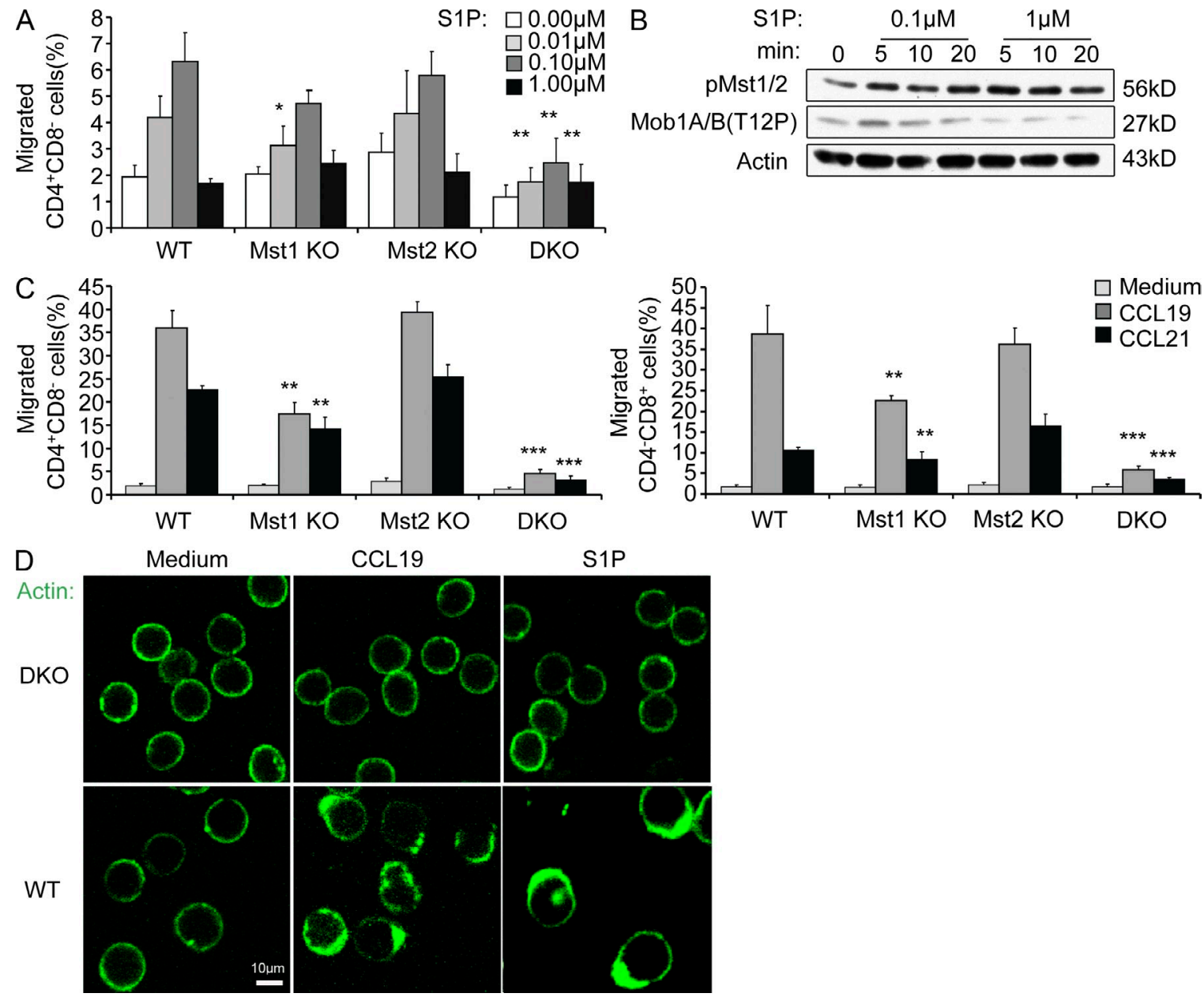

Figure 7. Chemotaxis and actin polarization are greatly inhibited in Mst1/Mst2-deficient thymocytes. (A and C) Thymocyte migration to S1P. Genotypes of WT and DKO as in Fig. 1. WT, Mst1-null (Mst1 KO), Vav-Cre+Mst2ff (Mst2 KO), and DKO thymocytes (106) were placed in the upper well; after $3 \mathrm{~h}$, the upper and lower wells were analyzed by flow cytometry for the number $\mathrm{CD} 4^{+} / \mathrm{CD} 8^{-}$cells. The fraction migrating to the lower well in response to S1P (A) at the concentrations shown or to CCL19 and CCL21 at $200 \mathrm{ng} / \mathrm{ml}$ (C) was calculated. The result of triplicate analyses is shown; a second experiment gave similar results. Comparisons were performed using the Student's $t$ test $\left({ }^{*}, P<0.05 ;{ }^{* *}, P<0.01 ;{ }^{* * *}, P<0.001\right)$. Error bars indicate $\pm S E M$. (B) A time course of S1P-stimulated Mob1A/B (T12) phosphorylation in WT thymocytes. (D) Actin polarization in CD90.2 thymocytes from WT and DKO mice $2 \mathrm{~min}$ after the addition of $0.1 \mu \mathrm{M} \mathrm{S1P}$ or $200 \mathrm{ng} / \mathrm{ml}$ CCL19. Data are representative of three experiments.

from rac1ff/rac2ff/lck-cre mice (Faroudi et al., 2010). Some of this difference is likely attributable to excessive intrathymic and postegress apoptosis in the Mst1/Mst2 DKO thymocytes; however, it is clear that the Mst1/Mst2 DKO thymocytes lack the ability to activate rhoA as well as rac, and so their defect in cytoskeletal regulation exceeds that engendered by the loss of the rac-specific Dock2 or both the rac1 + rac2 GTPases. As regards the role of Dock8, T cells from Dock8-deficient mice (Randall et al., 2011) do show some commonalities with the Mst1/Mst2-deficient SP thymocytes, most notably a failure to polarize LFA-1 or actin to the immune synapse. The Dock8-deficient mice also exhibit a

Figure 6. Differential homing of CD4+/CD8- thymocytes from WT, Mst1-null (1KO), and DKO mice into SLOs. (A-C) Genotypes as in Fig. 1. Representative flow cytometric profiles of a 50:50 mixture of CMF2HC (blue)- or CMFDA (green)-labeled CD4+/CD8 ${ }^{-}$thymocytes from WT and DKO mice (A), WT and Mst1 KO mice (B), and Mst1 KO and DKO mice (C) are shown before injection (BI) and when sampled from blood (PBL), spleen, axillary LNs (ALN), and mesenteric LNs (MLN) at 1 and $24 \mathrm{~h}$ after i.v. injection. The bar graphs show the ratios of labeled cells before injection and in lymphoid tissues as indicated; LNs including axillary (ALN), brachial (BLN), caudal (CLN), pancreatic (PLN), mesenteric (MLN) and inguinal (ILN) LNs. Data were pooled from three independent experiments. Each bar in A-C represents combined results from three mice of the indicated genotype. (D) The fraction of injected cells in the spleen residing in B cells follicles, as described in Materials and methods. CD45.2 is an alloantigen of CD45 expressed in all donor but not in recipient lymphoid cells. Data are combined from three independent experiments. Comparisons between WT and Mst1-null mice and WT and DKO mice were performed using the Student's $t$ test $(* *, P<0.01)$. (E) The relative recovery of dye-labeled cells in SLOs at 1 and $24 \mathrm{~h}$ after injection $(* *, P<0.01)$. Each bar represents combined results from three mice of the indicated genotype. (A-E) Error bars indicate \pm SEM. 


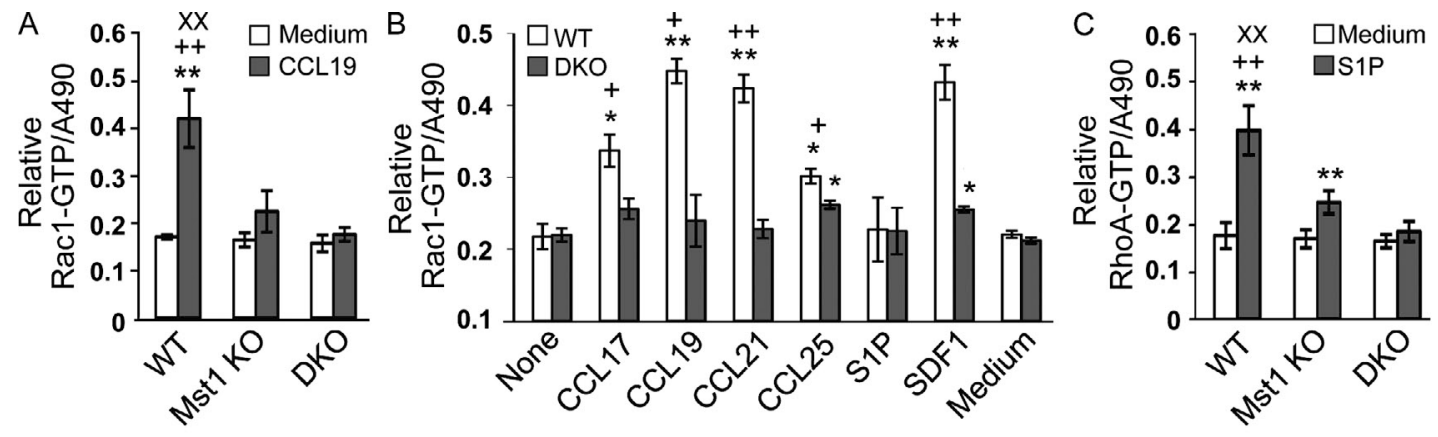

D WT Mst1 KO Mst2 KO DKO

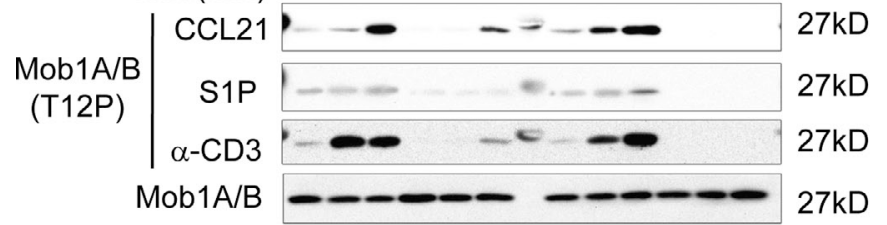

$E$

CCL19

SDF-1

Time(min) $\overline{0510} \overline{0510} \overline{0510} \overline{0510} \quad \overline{0510} \overline{0510} \overline{05100 \overline{510}}$

$\operatorname{Mob} 1 \mathrm{~A} / \mathrm{B}(\mathrm{T} 12 \mathrm{P})$

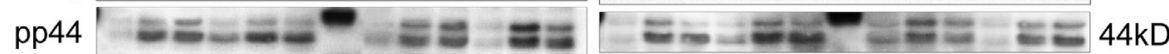

pp38 - - - - - - - - - - - - - - -

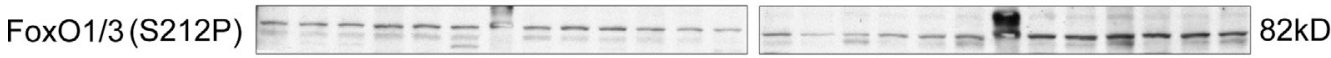

WT Mst1 KO Mst2 KO DKO

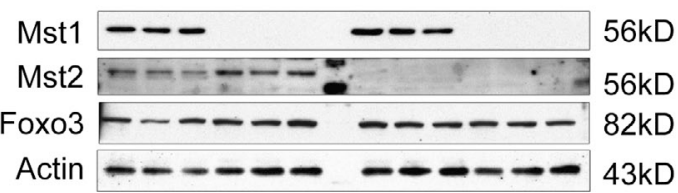

F $\quad$ Time(min) $\frac{\text { WT }}{0510} \frac{M s t 1 \mathrm{KO}}{0510} \frac{\mathrm{Mst} 2 \mathrm{KO}}{0510} \frac{\mathrm{DKO}}{0510}$

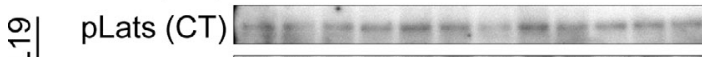

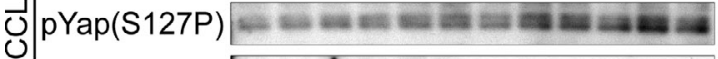

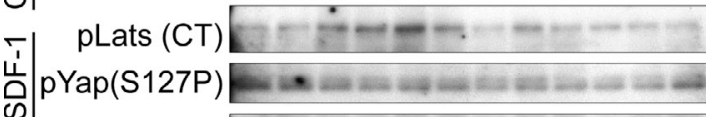

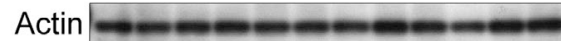

$56 \mathrm{kD}$

$56 \mathrm{kD}$

$82 \mathrm{kD}$

\begin{tabular}{|c|c|c|c|}
\hline & WT & DKO & \\
\hline & CCL19 PMA & CCL19 PMA & \\
\hline Time(min) & $\overline{0510} \overline{510}$ & $\begin{array}{l}0510 \\
510\end{array}$ & \\
\hline$\underset{\text { (T12P) }}{\text { Mob1A/B }}$ & $=0$ & & $27 \mathrm{kD}$ \\
\hline pLats (CT) & $-----\infty$ & $-3 v-v u$ & $127 \mathrm{kD}$ \\
\hline pYap(S127P) & Ever & 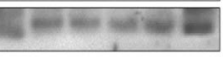 & $65 \mathrm{kD}$ \\
\hline Actin & -20- & -un & $43 \mathrm{kD}$ \\
\hline
\end{tabular}

Figure 8. Thymocyte signaling in response to chemokines and S1P. (A) The effect of CCL19 on rac1 GTP charging in WT, Mst1 KO, and DKO CD4 SP thymocytes; genotypes of WT and DKO as in Fig. 1. Cells were extracted before (open bars) and at 2 min after (closed bars) treatment with $200 \mathrm{ng} / \mathrm{ml}$ CCL19. Rac1 GTP charging was measured using a G-LISA kit (Cytoskeleton) according to manufacturer's instructions and read as absorbance at $490 \mathrm{~nm}$ $\left({ }^{* *}, P<0.01\right.$ WT at 2 min vs. at 0 min;,$++ P<0.01$ WT vs. $1 \mathrm{KO}$ at $2 \mathrm{~min} ; x_{1}, P<0.01$ WT vs. DKO at 2 min). (B) Rac 1 GTP charging was measured as in $A$ before and $2 \mathrm{~min}$ after the addition of the agents indicated to WT (open bars) or Mst1/Mst2 DKO (closed bars) thymocytes $\left({ }^{*}, \mathrm{P}<0.05 ;{ }^{* *}, \mathrm{P}<0.01 \mathrm{WT}\right.$ at 2 min vs. at 0 min;,$+ P<0.05 ;++, P<0.01$ WT vs. DKO at $2 \mathrm{~min}$ ). (C) The effect of $0.1 \mu \mathrm{M} \mathrm{S1P}(2 \mathrm{~min})$ on rhoA GTP charging in WT, Mst1 K0, and Mst1/ Mst2 DKO CD4 SP thymocytes. RhoA GTP charging was measured using a G-LISA kit ${ }^{* *}, P<0.01$ WT at 2 min vs. at 0 min;,$++ P<0.01$ WT vs. 1 KO at $2 \mathrm{~min} ; x_{1}, P<0.01$ WT vs. DKO at $\left.2 \mathrm{~min}\right)$. Each bar in A-C represents combined results from three mice of the indicated genotype. Error bars indicate $\pm S E M$. (D) Effect of $200 \mathrm{ng} / \mathrm{ml} \mathrm{CCL21,} 0.1 \mu \mathrm{M} \mathrm{S1P}$, and $1 \mu \mathrm{g} / \mathrm{ml}$ anti-CD3 antibody on Mob1(T12) phosphorylation in thymocytes. (E) The effect of $200 \mathrm{ng} / \mathrm{ml}$ CCL19 (left) and $100 \mathrm{ng} / \mathrm{ml}$ SDF1 (right) on Mob1A/B(T12), p44erk, p38, and Foxo1/3(S212) phosphorylation in thymocytes. The bottom panel shows polypeptide abundance. (F) The effect of $200 \mathrm{ng} / \mathrm{ml}$ CCL19, $100 \mathrm{ng} / \mathrm{ml}$ SDF1, and $50 \mathrm{ng} / \mathrm{ml}$ PMA on the phosphorylation of Lats 1/2 and Yap1 in thymocytes.

$50 \%$ decrease in peripheral naive $\mathrm{T}$ cells without fewer SP thymocytes or evidence of disturbed thymic differentiation. In reconstitution of irradiated mice with mixtures of WT and Dock 8 mutant bone marrow, Dock 8 mutant $\mathrm{T}$ cells contributed only $5 \%$ of circulating $\mathrm{T}$ cells, whereas thymic engraftment of Dock 8 mutant cells ranged from 30\% to 

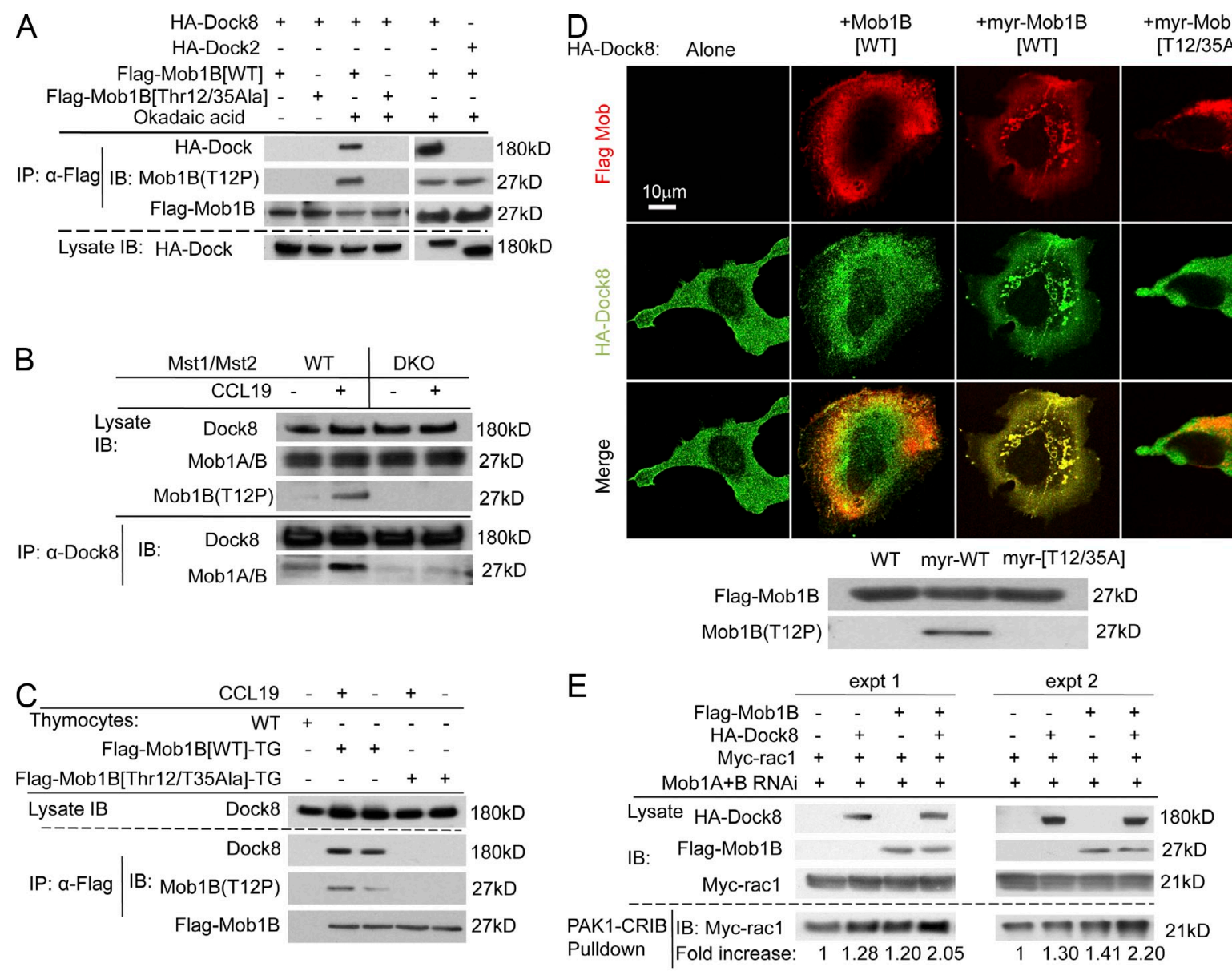

Figure 9. Mob1A/B phosphorylated by Mst1/Mst2 binds and regulates Dock8 but not Dock2. (A) Dock8 but not Dock2 binds specifically to phospho-Mob1. U2OS cell lines stably expressing Flag-Mob1B WT or Flag-Mob1B[Thr12Ala/Thr35Ala] were transfected with HA-Dock8 or HA-Dock2. After 48 h, OKA or carrier was added for $30 \mathrm{~min}$. The Flag-Mob1 immunoprecipitates were probed for Flag-Mob1B, Mob1(T12P), and HA-Dock8 or -Dock2. (B) CCl19 stimulates the Mst1/Mst2-dependent coprecipitation of Dock8 and Mob1A/B(T12) phosphorylation in mouse thymocytes. WT and DKO (genotypes as in Fig. 1) CD90.2+ thymocytes were treated with $250 \mathrm{ng} / \mathrm{ml} \mathrm{CCL19}$ or carrier for 5 min before extraction, and immunoprecipitations (IP) were performed using rabbit anti-Dock8. (C) Transgenic thymic Flag-Mob1B WT but not Flag-Mob1B[Thr12Ala/Thr35Ala] coprecipitates endogenous Dock8. Thymocytes from mice expressing Flag-Mob1B WT or Flag-Mob1B[Thr12Ala/Thr35Ala] driven by a CD2 promoter were treated with $250 \mathrm{ng} / \mathrm{ml}$ CCL19 or carrier for 5 min. Immunoprecipitations prepared with normal IgG or anti-Flag were probed for Dock8, Mob1B(T12P), and Flag-Mob1B. (D) Colocalization of Dock8 with Flag-Mob1BWT, Flag-myr-Mob1BWT, and Flag-Mob1B[Thr12Ala/Thr35Ala]. HA-tagged Dock8 was transiently expressed alone or with FlagMob1BWT, Flag-myr-Mob1BWT, and Flag-Mob1B[Thr12Ala/Thr35Ala] in U2OS cells. The proteins were visualized with antibody against Flag and HA, and colocalization is shown in yellow. Western blots (below the images) show that at similar levels of total Mob1B polypeptide, Flag-myr-Mob1B WT exhibits much higher phosphorylation than nonmyristolylated Flag-Mob1B WT. (E) Mob1B stimulates Dock8 GEF activity. 293T cells were cotransfected with Mycrac1 and a vector expressing shRNA against both Mob1A and Mob1B. Some cells also received HA-Dock8, or an RNA interference (RNAi)-insensitive FlagMob1B or both. After $24 \mathrm{~h}$, cell extracts were incubated with an excess of a GST-Pak1-CRIB domain fusion protein, and the GST pull-downs were probed for Myc-rac1. The ratio of Myc-rac in the pull-down fraction relative to that in the total lysate of cells receiving only myc-rac1 was set to one; other ratios were normalized to this value. Two independent experiments are shown. IB, immunoblot.

$22 \%$ to $16 \%$ of WT numbers for double-negative, DP, and SP thymocytes, respectively. Dock8-deficient humans exhibit a hyper-IgE form of combined immunodeficiency with low numbers of $\mathrm{T}$ and $\mathrm{B}$ cells and susceptibility to cutaneous viral infections and tumorigenesis, pointing to defective $\mathrm{T}$ cell function (Engelhardt et al., 2009; Zhang et al., 2009). Given the limited overlap between Dock8 and Mst1/Mst2 deficiency, it is clear that the loss of phospho-Mob1A/B activation of Dock8 can only be one of several factors contributing to the phenotypes of the Mst1/Mst2-deficient thymocytes. Deficient Dock8 GEF activity is unlikely to underlie the failure of S1P activation of rhoA or the accelerated apoptosis, so that other Mst1/Mst2 or P-Mob1A/B effectors remain to be uncovered. However, it is likely that the loss of Mob1A/B binding to Dock 8 contributes to the failure of chemokine-stimulated rac1 activation in Mst1/Mst2-deficient thymocytes and in turn to the failure of thymic egress. Moreover, the identification of Mst1/Mst2 regulation of Dock8 through Mob1A/B 
phosphorylation uncovers a new aspect of Mst1/Mst2 action and a new pathway for the regulation of rho family GTPases.

It is important to emphasize that both the upstream regulation and the outputs of the Mst1/Mst2-Mob1A/B cassette in the lymphoid system differ substantially as compared with epithelia. The hippo pathway, as first characterized in flies and subsequently in mammalian cell culture, is activated by cell-cell contact through adhesion receptors and has an antiproliferative, proapoptotic output that is mediated primarily by a phosphorylation-induced suppression of the proliferative, antiapoptotic transcriptional outputs of yorkie/Yap1, an oncogenic co-activator (Zhao et al., 2007; Pan, 2010; Halder and Johnson, 2011). In the canonical hippo pathway as operating in epithelia, the primary Mst1/Mst2 scaffold and partner is Salvador, which through its SARAH domain binds Mst1/Mst2 and through its WW domain binds Lats1/2, a Yap1 kinase. The Salvador-hippo-Lats complex is recruited to upstream regulators by complexes of Kibra-Merlin-Expanded. In contrast, the obligatory partner of Mst1/Mst2 in lymphoid cells is Nore1B/Rassf5b/RAPL, that like Salvador, binds Mst1/Mst2 through its carboxy-terminal SARAH domain, but unlike Salvador does not bind Lats $1 / 2$ and is recruited to upstream regulators through the ability of its Ras-Rap association domain to bind Rap1-GTP generated in response to ligand activated receptors (Katagiri et al., 2006; Avruch et al., 2009). The ability of Mst1/Mst2 to couple to the Lats1/2 kinases or other Yap1 kinases in lymphoid cells in response to physiological stimuli is minimal (Fig. 8 F; Zhou et al., 2008). As regards regulation, Mst1 in mouse liver exists predominantly as a constitutively active $36-\mathrm{kD}$ catalytic fragment with unrestricted access to the nucleus (Zhou et al., 2009). In lymphoid cells, Mst1/Mst2 occur only as full-length polypeptides that become activated only in response to ligand stimulation (Zhou et al., 2008, 2009). The high rate of apoptosis in the Mst1/Mst2-deficient thymocytes further illustrates the tissue-specific variation in the outputs of Mst1/Mst2. As in thymocytes, deletion of Mst1/Mst2 from mouse liver also eliminates Mob1 phosphorylation (Zhou et al., 2008) and causes high levels of reactive oxygen species (Choi et al., 2009); however, in contrast to the high rate of thymocyte apoptosis, Mst1/Mst2-deficient hepatocytes exhibit a marked resistance to Fas-induced apoptosis (Zhou et al., 2009). Thus, apart from Mob1 phosphorylation, the consequences of Mst1/Mst2 deficiency need to be established in each tissue, as they may not replicate those predicted from the canonical hippo pathway or from studies in transformed mammalian cells.

\section{MATERIALS AND METHODS}

Mob1A/Mob1B nomenclature. A recent change in the nomenclature of the Mob polypeptides (Human Gene Nomenclature Database) has caused the polypeptide we previously described (Praskova et al., 2008) as MOBKL1A (and which has also been called Mob1 and Mob4A) to be renamed Mob1B and the polypeptide we previously called MOBKL1B (and which has also been called Mob1, Mats1, and Mob4B) to be renamed Mob1A; the new nomenclature is used herein. Our antibodies raised against human GST-Mob1B (previously MOBKL1A) react equally with human Mob1A and Mob1B, which are $96 \%$ identical in amino acid sequence. Mob1 A and Mob1B are each phosphorylated at Thr12 and Thr35 comparably by either Mst1 or Mst2 (Praskova et al., 2008), and the phospho-specific antibodies against the Mob1A/B Thr12(PO4)-peptide and Thr35(PO4)-peptide, CSRSSKT(PO4)FKPKKNamide and CLKHAEAT(PO4)LGSGNamide, respectively, react similarly with the corresponding phosphorylated forms of Mob1A and Mob1B. Therefore, the endogenous polypeptides detected on immunoblots of tissue/cell extracts with the anti-Mob1B or the phosphospecific Mob1A/B antibodies are referred to herein as Mob1A/B.

Generation of transgenic Flag-Mst1[WT], Flag-Mst1[K59R], FlagMob1B[WT], and Flag-Mob1B[Thr12Ala/Thr35Ala] mice and Mst1/Mst2 DKO mice. The CD2-Flag-Mst1 and CD2-Flag-Mob1B transgenic constructs were made by cloning into the EcoRI site of the CD2 vector (de Boer et al., 2003), a gift from D. Kioussis (Medical Research Council National Institute for Medical Research, London, England, UK). Two founders each were obtained and bred. Transgenic heterozygote mice issued from these founders were studied and compared with nontransgenic siblings raised in identical conditions. Genotyping was performed on tail DNAs by the following primers: CD2 primer (5'-CCCCTAAGAACAGCTTTCCA-3'), Mst1 primer (5'-TGTGGGAGGAGGGTTTGTAG-3'), and Mob1B primer $\left(5^{\prime}-\right.$ TTTAGAAGAGCGACTACCAA-3'). Mst $1^{-/}-\mathrm{Mst}^{2 \mathrm{ff}^{\mathrm{f}}}$ mice were generated as described previously (Zhou et al., 2009). Vav-Cre and Lck-Cre mice were purchased from the Jackson Laboratory. Mst1-null mice with Mst2 deleted in hematopoietic cells and lymphocytes were generated by breeding Mst1-null/Mst2 $2^{\text {ff }}$ mice with Vav-Cre or Lck-Cre mice. When examining Vav-Cre ${ }^{+} \mathrm{Mst} 1$-nullMst $2^{f f}$ mice, $\mathrm{Vav}_{-} \mathrm{Cre}^{+} \mathrm{Mst}^{+/+} \mathrm{Mst}^{+/+}$ mice were used as controls; when examining Lck-Cre $^{+}$Mst1-nullMst $2^{\text {ff }}$ mice, $\mathrm{Lck}_{-} \mathrm{Cre}^{+} \mathrm{Mst}^{+/+} \mathrm{Mst}^{+/+}$mice were used as controls. Animal protocols were approved by the Institutional Animal Care and Use Committee of Massachusetts General Hospital. Comparisons were made using littermates.

Cell isolation and Western blotting. CD90.2-positive thymocytes were isolated by using Thy1.2 MicroBeads according to the manufacturer's instructions (Miltenyi Biotec). Before CCL19 and SDF-1 stimulation, the cells were rested at $37^{\circ} \mathrm{C}$ for $2-3 \mathrm{~h}$ in RPMI 1640 complete medium containing 10\% FBS, 25 mM Hepes, 2 mM L-glutamine, 50 M 2-mercaptoethanol, $1 \%$ nonessential amino acid, and $2 \mathrm{mM}$ sodium pyruvate. Cells were lysed in ice-cold lysis buffer containing $1 \%$ Triton X-100, $50 \mathrm{mM}$ Tris-HCl, $\mathrm{pH}$ 7.4, $10 \%$ glycerol, $150 \mathrm{mM} \mathrm{NaCl}, 2 \mathrm{mM}$ EDTA, $50 \mathrm{mM} \mathrm{NaF}, 10 \mathrm{mM}$ $\mathrm{Na} 3 \mathrm{VO} 4$, complete Mini protease inhibitor mixture tablet (Roche), and $2 \mathrm{mM}$ PMSF. The extracted proteins were subjected to SDS-PAGE and transferred to polyvinylidene fluoride membranes. The following antibodies were used for immunoblotting: anti-YAP, anti-P-YAP (Cell Signaling Technology), anti-phospho-p38 (Cell Signaling Technology), anti-phospho-p44 (Cell Signaling Technology), anti-Foxo3 (Cell Signaling Technology), anti-p-Foxo1/3 (Invitrogen), anti-KLF2 (Sigma-Aldrich), and antiactin (Sigma-Aldrich). The antibodies against Mst1, Mst2, Nore1b, Lats1, phosphoMobkl1A/B (Thr12P), and phospho-Lats1 carboxy terminus have been described previously (Praskova et al., 2008). Horseradish peroxidaseconjugated secondary antibodies against rabbit or mouse IgG were obtained from Jackson ImmunoResearch Laboratories, Inc. The specific bands were visualized using the SuperSignal West Pico/Femto substrate (Thermo Fisher Scientific).

Immunofluorescence staining. Immunofluorescence staining of thymus, spleen, and LN sections was performed as described previously (Zhou et al., 2008, 2009). Thymus, spleen, or LNs were harvested and immediately frozen in OCT compound (Tissue-Tek). $6-\mu \mathrm{m}$-thick sections were cut and stored at $-80^{\circ} \mathrm{C}$ until use. All subsequent manipulations were performed at room temperature. Sections were air dried overnight, fixed in ice-cold acetone for $10 \mathrm{~min}$, air dried briefly, blocked with 5\% normal horse serum for $20 \mathrm{~min}$, and incubated with the indicated antibodies: anti-CD4-PE, anti-B220-FITC, pan-cytokeratin-FITC (BD), and biotin-conjugated antiCD45.2 at 1:50 dilution for $2 \mathrm{~h}$. Streptavidin conjugated with Texas red (Jackson ImmunoResearch Laboratories, Inc.) was used at 1:1,000 dilution 
for CD45.2 detection. Sections were rinsed in PBS (three times, 5 min each) and mounted with mounting medium (Vectashield). Digital images were acquired by using an epifluorescence microscope (Eclipse 800; Nikon) equipped with a charge-coupled device camera (Orca 100; Hamamatsu Photonics). Epifluorescence images were analyzed using IPLab version 3.2.4 image processing software (Scanalytics) and imported into Photoshop version 7.0 (Adobe Systems) for production of the final figures.

Flow cytometry. Single cell suspensions of thymus, peripheral blood, spleen, or LN were resuspended in PBS with 1\% BSA and blocked with CD16/CD32 (Fc III/II receptor; BD). The cells were then counted and stained with the indicated antibodies. Antibodies were obtained from eBioscience. Flow cytometry was performed on an LSR-II (BD) and analyzed with FlowJo software (Tree Star).

Intrathymic FITC labeling. Intrathymic FITC injections were performed as described previously (Dong et al., 2009). In brief, a ventral midline incision was made one-third down the sternum to expose the thymus. A Hamilton syringe was used to inject $10 \mu \mathrm{l}$ of a $1 \mathrm{mg} / \mathrm{ml}$ FITC solution (Sigma-Aldrich). The skin incision was closed with silk sutures, and mice were allowed to recover under a heat source. At day 1 after injection, cells in the blood, spleen, and LNs were monitored for FITC incorporation.

Cell-labeling CD45.2-positive cells and adoptive transfer. CD4 SP thymocytes were isolated and labeled with $2 \mu \mathrm{M}$ CellTracker green CMFDA (5-chloromethylfluorescein diacetate) or $2.5 \mu \mathrm{M}$ CellTracker blue CMF2HC (4-chloromethyl-6,8-difluoro-7-hydroxycoumarin) for $15 \mathrm{~min}$ at $37^{\circ} \mathrm{C}$ according to manufacturer's instructions (Invitrogen). Two million total thymocytes at a 1:1 ratio were injected into the tail vein of C57BL6 mice. The labeled CD4 from peripheral blood, spleen, and LNs was analyzed separately by flow cytometry 1 and $24 \mathrm{~h}$ after injection. To define the intrasplenic localization, $10^{6} \mathrm{CD} 45.2^{+} \mathrm{CD} 4^{+} \mathrm{SP}$ thymocytes isolated from each genotype were injected into the tail vein of B6.SJL$\operatorname{Ptprc}^{\mathrm{a}} / \mathrm{Pepc}^{\mathrm{b}} /$ BoyJ mice (The Jackson Laboratory). Spleens and LNs were harvested $24 \mathrm{~h}$ thereafter and embedded in OCT for frozen section. After anti-CD45.2 and B220 staining (to define follicles), the number of CD45.2 $2^{+}$ cells in six intrafollicular regions and in six similar sized areas of red pulp were counted (a total of $\sim 1,500$ cells of each genotype), and the percentage of total $\mathrm{CD} 45.2^{+}$cells in the $\mathrm{CD} 45.1^{+}$recipient spleens that were found within splenic follicles was determined.

Chemotaxis assays. Migration assays were conducted as described previously (Zhou et al., 2008). In brief, $0.5 \mathrm{ml}$ RPMI medium 1640 containing $200 \mathrm{ng} / \mathrm{ml} \mathrm{CCL19,} \mathrm{CCL21} \mathrm{(R \& D} \mathrm{Systems),} \mathrm{and} \mathrm{the} \mathrm{indicated} \mathrm{concentra-}$ tion of S1P (Sigma-Aldrich) was added to the lower chamber. One million thymocytes in $150 \mu \mathrm{l}$ of media were then added to the upper chamber of $5-\mu \mathrm{m}$ pore, polycarbonate $24-$ well tissue culture inserts (Costar) and incubated for $3 \mathrm{~h}$ at $37^{\circ} \mathrm{C}$ in $5 \% \mathrm{CO}_{2}$. The thymocytes from the input and lower chambers were counted and stained with CD4-PE and CD8-FITC for FACS analysis. Percentage of migration was calculated for each flow cytometrydefined subset by dividing the number of that subset in the input into the number of cells migrated. All chemotaxis data represent the mean of triplicate wells performed in two experiments.

PBL counts. Mice were anesthetized with isoflurane before blood collection by tail tip transection. Whole-blood samples $(200-300 \mu \mathrm{l})$ were collected into EDTA blood collection tubes (BD) and analyzed in duplicate on a Hemavet 850FS Multi Species Hematology System (Drew Scientific) programmed with mouse hematology settings.

Measurements of S1P in thymus and serum. Thymus was homogenized with ice-cold lysis buffer, centrifuged, and used for S1P extraction. Samples were processed and analyzed by the Lipidomics Analytical Core of the University of South Carolina.
FTY720 administration and S1pr1 staining. Mice were given an i.p. injection of $100 \mu \mathrm{l}$ PBS or $100 \mu \mathrm{l}$ PBS containing $10 \mathrm{mg} / \mathrm{kg}$ FTY720. $24 \mathrm{~h}$ thereafter, thymocytes were isolated and analyzed by flow cytometry. In brief, rabbit anti-S1pr1 primary (a gift from J. Cyster, University of California, San Francisco, San Francisco, CA) and biotin-labeled goat anti-rabbit Ig secondary $(1: 50 ; \mathrm{BD})$ antibodies were presorbed for at least $15 \mathrm{~min}$ in FACS buffer containing $4 \%$ normal mouse serum. One million thymocytes suspended in $25 \mu \mathrm{l}$ of flow buffer were incubated with anti-S1pr1 for $1.5 \mathrm{~h}$ on ice. Cells were washed once with FACS buffer and then stained with secondary antibody for $20 \mathrm{~min}$ on ice. After washing with flow buffer, cells were further stained with Streptavidin-APC for $20 \mathrm{~min}$ on ice (1:200 dilution; Invitrogen) and analyzed by flow cytometry.

Northern blot analysis. Total RNA was extracted from $5 \times 10^{6}$ cells with TRIZOL (Invitrogen). $20 \mu \mathrm{g}$ RNA was separated by electrophoresis in $2 \%$ denaturing formaldehyde agarose gels and transferred to a nylon membrane (Hybond N; GE Healthcare). RNA was cross-linked to the membranes by UV light. After prehybridization, the membrane was hybridized with the full-length S1pr1 cDNAs, labeled with ${ }^{32} \mathrm{P}$ by using a random primer DNA labeling kit (QIAGEN). The membrane was washed and exposed to radiographic film.

BrdU administration and detection. WT and DKO-Lck mice received two i.p. injections of BrdU (1 mg each at 4-h intervals). Thymocytes were harvested $1 \mathrm{~h}$ after the second injection (Lucas et al., 1993). BrdU incorporation was detected using the APC BrdU Flow kit (BD). After surface staining, cells were fixed and permeabilized with Cytofix/Cytoperm buffer for 15-30 min on ice and then treated with DNase to expose incorporated BrdU. Subsequently, cells were stained with APC-conjugated anti-BrdU antibody and then analyzed by FACS.

Cells and chemokines. U2OS cells stably expressing recombinant FlagMob1[WT] or [Thr12Ala/Thr35Ala] were described previously (Praskova et al., 2008). The chemokines CCL17, CCL19, CCL21, CCL25, SDF1, and S1P were purchased from R\&D Systems. Transfection was performed using Lipofectamine 2000 (Invitrogen).

Plasmids. For transient expression, a plasmid encoding doxycycline-inducible short hairpin RNAs (shRNAs) against both endogenous Mob1A and Mob1B was previously described; some versions also contained an shRNA-resistant cDNA encoding Flag-Mob1B[WT] or [Thr12Ala/Thr35Ala] (Praskova et al., 2008). The cDNAs encoding human Dock8 and Dock2 were cloned into the EcoRV and XhoI sites of pcDNA3 vector (Invitrogen) with an HA tag on the $5^{\prime}$ end. The following primers were used during cloning: Dock8 forward, 5'-ATTCGATATCCAATGACACACCTGAACAGC-3'; and reverse, 5'-ATTACTCGAGTTAGCTGCCCTGTGAC-3'; and Dock2 forward, 5'-ATTCGATATCCAATGGCCCCCTGGCGCAAA-3'; and reverse, 5' -ATTACTCGAGTCACAGGTCCGTGGACAGCG-3' .

Assay of endogenous rac1/rhoA GTP charging. SP thymocytes were rested in RPMI 1640 medium supplemented with $0.1 \%$ BSA for $2 \mathrm{~h}$ at $37^{\circ} \mathrm{C}$. Medium alone or medium containing the following chemokines (final concentration) was added (250 ng/ml CCL17, $250 \mathrm{ng} / \mathrm{ml} \mathrm{CCL19,}$ $250 \mathrm{ng} / \mathrm{ml}$ CCL21, $250 \mathrm{ng} / \mathrm{ml} \mathrm{CCL25,} 200 \mathrm{ng} / \mathrm{ml} \mathrm{SDF-1,} \mathrm{or} 100 \mathrm{nM} \mathrm{S1P)}$ to $3 \times 10^{5}$ thymocytes and terminated after $2 \mathrm{~min}$. Cell extracts were assayed for rac1 or rhoA GTP charging using the absorbance based G-LISA kits (Cytoskeleton). The endogenous Rac or Rho GTPase activity is expressed as absorbance readings at $490 \mathrm{~nm}$. Experiments are performed in duplicate or triplicate; mean values $\pm \mathrm{SD}$ are shown.

Assay of recombinant rac1/rhoA GTP charging. 293T cells seeded in a $100-\mathrm{mm}$ dish with $50 \%$ confluence were transfected with the following constructs, in combinations as indicated in Fig. $9 \mathrm{E}: 6 \mu \mathrm{g}$ HA-Dock8, $2 \mu \mathrm{g}$ myc-rac1, $2 \mu \mathrm{g}$ shMob1A + shMob1B, $2 \mu \mathrm{g}$ shMob1A + shMob1B + FlagMob1A(WT), or $6 \mu \mathrm{g}$ of empty pCDNA3-HA vector. $48 \mathrm{~h}$ after transfection, cells were lysed with binding buffer $(50 \mathrm{mM}$ Tris- $\mathrm{HCl}, \mathrm{pH}$ 7.5, $150 \mathrm{mM}$ 
$\mathrm{NaCl}, 10 \mathrm{mM} \mathrm{MgCl} 2$, 1\% Triton X-100, 1 mM DTT, 2 mM Na3VO4, and $1 \times$ EDTA-free protease inhibitor cocktail [Roche]). $20 \mu \mathrm{g}$ Escherichia coli purified GST-PAK1-CRIB preloaded on GSH Sepharose was incubated with the precleared cell lysates at $4^{\circ} \mathrm{C}$ for $1 \mathrm{~h}$. After three washes with binding buffer, the amount of rac-GTP bound to the beads was determined by Flag immunoblot after SDS-PAGE.

Antibodies and immunoprecipitation. Polyclonal antibody against Dock8 was generated by injecting rabbits with a synthetic peptide (SQKRDSFHRSSFRKC) coupled to KLH. M2 antibody against Flag tag bound to agarose was purchased (Sigma-Aldrich). To examine the interaction of endogenous Mob1/Dock8, thymocytes + naive splenic T cells were rested for $2 \mathrm{~h}$ in RPMI 1640 supplemented with $0.1 \%$ BSA. Cells were harvested $5 \mathrm{~min}$ after the addition of $250 \mathrm{ng} / \mathrm{ml} \mathrm{CCL19}$ or media. Cells were extracted in immunoprecipitation buffer $(20 \mathrm{mM}$ Tris- $\mathrm{HCl}, \mathrm{pH} 7.5,150 \mathrm{mM} \mathrm{NaCl}$, $1 \mathrm{mM}$ EDTA, $1 \mathrm{mM}$ EGTA, $20 \mathrm{mM} \beta$-glycerophosphate, $50 \mathrm{mM} \mathrm{NaF}$, $1 \mathrm{mM} \mathrm{Na}_{3} \mathrm{VO}_{4}, 1 \%$ Triton $\mathrm{X}-100$, and $1 \times$ protease inhibitor cocktail [Roche]). $10 \mu \mathrm{g}$ anti-Dock8 antibody preloaded on protein A beads or a comparable amount of normal rabbit $\operatorname{IgG}$ was added to the extracts. For the interaction between recombinant proteins, $\mathrm{U} 2 \mathrm{OS}$ cells stably expressing Flag-Mob1B[WT] or [Thr12Ala/Thr35Ala] (Praskova et al., 2008) were transfected with HA-Dock8 or HA-Dock2 constructs. 24 h later, cells were treated with $1 \mu \mathrm{m}$ OKA for $30 \mathrm{~min}$ or carrier and extracted 30 min later in immunoprecipitation buffer. $10 \mu \mathrm{l} 2$ anti-Flag affinity gel was applied for capturing recombinant Flag-Mob1B. The beads were washed three times with immunoprecipitation buffer before SDS-PAGE.

We thank J. Cyster for the anti-S1pr1 antibody used for flow cytometry and P. Aspenström for Dock8 antiserum used in initial experiments.

This work was supported in part by the R01 awards CA136567 (to J. Avruch) and DK17776 (to J. Avruch) and institutional funds. D. Zhou is supported by T32DK007028, the Fundamental Research Funds for the Central Universities of China (project number 2010111079), and the Science Planning Program of Fujian Province (2009J1010).

The authors have no financial conflicts to disclose.

Submitted: 11 August 2011

Accepted: 13 February 2012

\section{REFERENCES}

Avruch, J., R. Xavier, N. Bardeesy, X.F. Zhang, M. Praskova, D. Zhou, and F. Xia. 2009. Rassf family of tumor suppressor polypeptides. J. Biol. Chem. 284:11001-11005. http://dx.doi.org/10.1074/jbc.R800073200

Bichsel, S.J., R. Tamaskovic, M.R. Stegert, and B.A. Hemmings. 2004. Mechanism of activation of NDR (nuclear Dbf2-related) protein kinase by the hMOB1 protein. J. Biol. Chem. 279:35228-35235. http:// dx.doi.org/10.1074/jbc.M404542200

Boursalian, T.E., J. Golob, D.M. Soper, C.J. Cooper, and P.J. Fink. 2004. Continued maturation of thymic emigrants in the periphery. Nat. Immunol. 5:418-425. http://dx.doi.org/10.1038/ni1049

Bromley, S.K., T.R. Mempel, and A.D. Luster. 2008. Orchestrating the orchestrators: Chemokines in control of $\mathrm{T}$ cell traffic. Nat. Immunol. 9:970-980. http://dx.doi.org/10.1038/ni.f.213

Bunting, M.D., I. Comerford, and S.R. McColl. 2011. Finding their niche: Chemokines directing cell migration in the thymus. Immunol. Cell Biol. 89:185-196. http://dx.doi.org/10.1038/icb.2010.142

Carlson, C.M., B.T. Endrizzi, J. Wu, X. Ding, M.A. Weinreich, E.R. Walsh, M.A. Wani, J.B. Lingrel, K.A. Hogquist, and S.C. Jameson. 2006. Kruppel-like factor 2 regulates thymocyte and T-cell migration. Nature. 442:299-302. http://dx.doi.org/10.1038/nature04882

Choi, J., S. Oh, D. Lee, H.J. Oh, J.Y. Park, S.B. Lee, and D.S. Lim. 2009. Mst1-FoxO signaling protects naïve $\mathrm{T}$ lymphocytes from cellular oxidative stress in mice. PLoS ONE. 4:e8011. http://dx.doi.org/10.1371/ journal.pone. 0008011
Côté, J.F., and K. Vuori. 2007. GEF what? Dock180 and related proteins help Rac to polarize cells in new ways. Trends Cell Biol. 17:383-393. http://dx.doi.org/10.1016/j.tcb.2007.05.001

de Boer, J., A. Williams, G. Skavdis, N. Harker, M. Coles, M. Tolaini, T. Norton, K. Williams, K. Roderick, A.J. Potocnik, and D. Kioussis. 2003. Transgenic mice with hematopoietic and lymphoid specific expression of Cre. Eur. J. Immunol. 33:314-325. http://dx.doi.org/10.1002/ immu. 200310005

Dong, Y., X. Du, J. Ye, M. Han, T. Xu, Y. Zhuang, and W. Tao. 2009. A cell-intrinsic role for Mst1 in regulating thymocyte egress. J. Immunol. 183:3865-3872. http://dx.doi.org/10.4049/jimmunol.0900678

Drennan, M.B., D. Elewaut, and K.A. Hogquist. 2009. Thymic emigration: sphingosine-1-phosphate receptor-1-dependent models and beyond Eur. J. Immunol. 39:925-930. http://dx.doi.org/10.1002/eji.200838912

Engelhardt, K.R., S. McGhee, S. Winkler, A. Sassi, C. Woellner, G. LopezHerrera, A. Chen, H.S. Kim, M.G. Lloret, I. Schulze, et al. 2009. Large deletions and point mutations involving the dedicator of cytokinesis 8 (DOCK8) in the autosomal-recessive form of hyper-IgE syndrome. J. Allergy Clin. Immunol. 124:1289-1302: e4. (published erratum appears in J. Allergy Clin. Immunol. 2010. 125:743) http://dx.doi.org/10.1016/ j.jaci.2009.10.038

Faroudi, M., M. Hons, A. Zachacz, C. Dumont, R. Lyck, J.V. Stein, and V.L. Tybulewicz. 2010. Critical roles for Rac GTPases in T-cell migration to and within lymph nodes. Blood. 116:5536-5547. http://dx.doi.org/ 10.1182/blood-2010-08-299438

Fukui, Y., O. Hashimoto, T. Sanui, T. Oono, H. Koga, M. Abe, A. Inayoshi, M. Noda, M. Oike,T. Shirai, and T. Sasazuki. 2001. Haematopoietic cell-specific CDM family protein DOCK2 is essential for lymphocyte migration. Nature. 412:826-831. http://dx.doi.org/10.1038/35090591

Gomez, T.S., and D.D. Billadeau. 2008. T cell activation and the cytoskeleton: you can't have one without the other. Adv. Immunol. 97:1-64. http://dx.doi.org/10.1016/S0065-2776(08)00001-1

Halder, G., and R.L. Johnson. 2011. Hippo signaling: Growth control and beyond. Development. 138:9-22. http://dx.doi.org/10.1242/dev.045500

Hergovich, A. 2011. MOB control: Reviewing a conserved family of kinase regulators. Cell. Signal. 23:1433-1440. http://dx.doi.org/10.1016/ j.cellsig.2011.04.007

Katagiri, K., N. Ohnishi, K. Kabashima, T. Iyoda, N. Takeda, Y. Shinkai, K. Inaba, and T. Kinashi. 2004. Crucial functions of the Rap1 effector molecule RAPL in lymphocyte and dendritic cell trafficking. Nat. Immunol. 5:1045-1051. http://dx.doi.org/10.1038/ni1111

Katagiri, K., M. Imamura, and T. Kinashi. 2006. Spatiotemporal regulation of the kinase Mst1 by binding protein RAPL is critical for lymphocyte polarity and adhesion. Nat. Immunol. 7:919-928. http://dx.doi.org/10.1038/ ni1374

Katagiri, K., T. Katakai, Y. Ebisuno, Y. Ueda, T. Okada, and T. Kinashi. 2009. Mst1 controls lymphocyte trafficking and interstitial motility within lymph nodes. EMBO J. 28:1319-1331. http://dx.doi.org/10 .1038/emboj.2009.82

Lehtinen, M.K., Z. Yuan, P.R. Boag, Y. Yang, J. Villén, E.B. Becker, S. DiBacco, N. de la Iglesia, S. Gygi, T.K. Blackwell, and A. Bonni. 2006. A conserved MST-FOXO signaling pathway mediates oxidative-stress responses and extends life span. Cell. 125:987-1001. http://dx.doi .org/10.1016/j.cell.2006.03.046

Lei, Y., C. Liu, F. Saito, Y. Fukui, and Y. Takahama. 2009. Role of DOCK2 and DOCK180 in fetal thymus colonization. Eur. J. Immunol. 39:2695-2702. http://dx.doi.org/10.1002/eji.200939630

Love, P.E., and A. Bhandoola. 2011. Signal integration and crosstalk during thymocyte migration and emigration. Nat. Rev. Immunol. 11:469-477. http://dx.doi.org/10.1038/nri2989

Lucas, B., F. Vasseur, and C. Penit. 1993. Normal sequence of phenotypic transitions in one cohort of 5-bromo-2'-deoxyuridine-pulse-labeled thymocytes. Correlation with $\mathrm{T}$ cell receptor expression. J. Immunol. 151 4574-4582.

Meller, N., S. Merlot, and C. Guda. 2005. CZH proteins: A new family of Rho-GEFs. J. Cell Sci. 118:4937-4946. http://dx.doi.org/10 $.1242 /$ jcs. 02671

Nishikimi, A., H. Fukuhara, W. Su, T. Hongu, S. Takasuga, H. Mihara, Q. Cao, F. Sanematsu, M. Kanai, H. Hasegawa, et al. 2009. Sequential 
regulation of DOCK2 dynamics by two phospholipids during neutrophil chemotaxis. Science. 324:384-387. http://dx.doi.org/10.1126/ science. 1170179

Pan, D. 2010. The hippo signaling pathway in development and cancer. Dev. Cell. 19:491-505. http://dx.doi.org/10.1016/j.devcel.2010.09.011

Pearse, G. 2006. Normal structure, function and histology of the thymus. Toxicol. Pathol. 34:504-514. http://dx.doi.org/10.1080/ 01926230600865549

Petrie, H.T., and J.C. Zúñiga-Pflücker. 2007. Zoned out: Functional mapping of stromal signaling microenvironments in the thymus. Annu. Rev. Immunol. 25:649-679. http://dx.doi.org/10.1146/annurev.immunol 23.021704 .115715

Praskova, M., A. Khoklatchev, S. Ortiz-Vega, and J. Avruch. 2004. Regulation of the MST1 kinase by autophosphorylation, by the growth inhibitory proteins, RASSF1 and NORE1, and by Ras. Biochem. J. 381:453-462. http://dx.doi.org/10.1042/BJ20040025

Praskova, M., F. Xia, and J. Avruch. 2008. MOBKL1A/MOBKL1B phosphorylation by MST1 and MST2 inhibits cell proliferation. Curr. Biol. 18:311-321. http://dx.doi.org/10.1016/j.cub.2008.02.006

Randall, K.L., S.S. Chan, C.S. Ma, I. Fung, Y. Mei, M. Yabas, A. Tan, P.D. Arkwright, W. Al Suwairi, S.O. Lugo Reyes, et al. 2011. DOCK8 deficiency impairs CD8 T cell survival and function in humans and mice. J. Exp. Med. 208:2305-2320. http://dx.doi.org/10.1084/jem.20110345

Reif, K., and J. Cyster. 2002. The CDM protein DOCK2 in lymphocyte migration. Trends Cell Biol. 12:368-373. http://dx.doi.org/ 10.1016/S0962-8924(02)02330-9

Sanui, T., A. Inayoshi, M. Noda, E. Iwata, J.V. Stein, T. Sasazuki, and Y. Fukui. 2003a. DOCK2 regulates Rac activation and cytoskeletal reorganization through interaction with ELMO1. Blood. 102:2948-2950. http://dx.doi.org/10.1182/blood-2003-01-0173

Sanui, T., A. Inayoshi, M. Noda, E. Iwata, M. Oike, T. Sasazuki, and Y Fukui. 2003b. DOCK2 is essential for antigen-induced translocation of TCR and lipid rafts, but not PKC-theta and LFA-1, in T cells. Immunity. 19:119-129. http://dx.doi.org/10.1016/S1074-7613(03)00169-9

Sensken, S.C., C. Bode, M. Nagarajan, U. Peest, O. Pabst, and M.H. Gräler. 2010. Redistribution of sphingosine 1-phosphate by sphingosine kinase 2 contributes to lymphopenia. J. Immunol. 184:4133-4142. http://dx.doi.org/10.4049/jimmunol.0903358

Stam, J.C., F. Michiels, R.A. van der Kammen, W.H. Moolenaar, and J.G. Collard. 1998. Invasion of T-lymphoma cells: Cooperation between Rho family GTPases and lysophospholipid receptor signaling. EMBO J. 17:4066-4074. http://dx.doi.org/10.1093/emboj/17.14.4066
Takahama, Y. 2006. Journey through the thymus: Stromal guides for T-cell development and selection. Nat. Rev. Immunol. 6:127-135. http://dx.doi .org/10.1038/nri1781

Thompson, G., D. Owen, P.A. Chalk, and P.N. Lowe. 1998. Delineation of the Cdc42/Rac-binding domain of p21-activated kinase. Biochemistry. 37:7885-7891. http://dx.doi.org/10.1021/bi980140+

Tybulewicz, V.L., and R.B. Henderson. 2009. Rho family GTPases and their regulators in lymphocytes. Nat. Rev. Immunol. 9:630-644. http:// dx.doi.org/10.1038/nri2606

von Boehmer, H., I. Aifantis, F. Gounari, O. Azogui, L. Haughn, I. Apostolou, E. Jaeckel, F. Grassi, and L. Klein. 2003. Thymic selection revisited: how essential is it? Immunol. Rev. 191:62-78. http://dx.doi .org/10.1034/j.1600-065X.2003.00010.x

Ward, S.G., and F.M. Marelli-Berg. 2009. Mechanisms of chemokine and antigen-dependent T-lymphocyte navigation. Biochem. J. 418:13-27. http://dx.doi.org/10.1042/BJ20081969

Yagi, H., R. Kamba, K. Chiba, H. Soga, K. Yaguchi, M. Nakamura, and T. Itoh. 2000. Immunosuppressant FTY720 inhibits thymocyte emigration. Eur. J. Immunol. 30:1435-1444. http://dx.doi.org/10.1002/ (SICI) 1521-4141(200005)30:5<1435::AID-IMMU1435>3.0.CO;2-O

Zhang, D.J., Q. Wang, J. Wei, G. Baimukanova, F. Buchholz, A.F. Stewart, X. Mao, and N. Killeen. 2005. Selective expression of the Cre recombinase in late-stage thymocytes using the distal promoter of the Lck gene. J. Immunol. 174:6725-6731.

Zhang, Q., J.C. Davis, I.T. Lamborn, A.F. Freeman, H. Jing, A.J. Favreau, H.F. Matthews, J. Davis, M.L. Turner, G. Uzel, et al. 2009. Combined immunodeficiency associated with DOCK8 mutations. N. Engl. J. Med. 361:2046-2055. http://dx.doi.org/10.1056/NEJMoa0905506

Zhao, B., X. Wei, W. Li, R.S. Udan, Q. Yang, J. Kim, J. Xie, T. Ikenoue, J. Yu, L. Li, et al. 2007. Inactivation of YAP oncoprotein by the Hippo pathway is involved in cell contact inhibition and tissue growth control. Genes Dev. 21:2747-2761. http://dx.doi.org/10.1101/gad.1602907

Zhou, D., B.D. Medoff, L. Chen, L. Li, X.F. Zhang, M. Praskova, M. Liu, A. Landry, R.S. Blumberg, V.A. Boussiotis, et al. 2008. The Nore1B/ Mst1 complex restrains antigen receptor-induced proliferation of naïve T cells. Proc. Natl. Acad. Sci. USA. 105:20321-20326. http://dx.doi .org/10.1073/pnas.0810773105

Zhou, D., C. Conrad, F. Xia, J.S. Park, B. Payer, Y. Yin, G.Y. Lauwers, W. Thasler, J.T. Lee, J. Avruch, and N. Bardeesy. 2009. Mst1 and Mst2 maintain hepatocyte quiescence and suppress hepatocellular carcinoma development through inactivation of the Yap1 oncogene. Cancer Cell 16:425-438. http://dx.doi.org/10.1016/j.ccr.2009.09.026 